\title{
Silica nanoparticle exposure during the neonatal period impairs hippocampal precursor proliferation and social behavior later in life
}

This article was published in the following Dove Press journal: International Journal of Nanomedicine

\author{
Jingjing $\mathrm{Fu}^{1,2, *}$ \\ Junwei $\mathrm{Gao}^{2, *}$ \\ Linji Gong ${ }^{3,4}$ \\ Yuanyuan $\mathrm{Ma}^{\prime}$ \\ Haiwei $X u^{5}$ \\ Zhanjun $\mathrm{Gu}^{3,4}$ \\ Jingci Zhu' \\ Xiaotang Fan²
}

'School of Nursing, Third Military Medical University, Chongqing 400038, China; ${ }^{2}$ Department of Developmental Neuropsychology, School of Psychology, Third Military Medical University, Chongqing 400038, China; ${ }^{3}$ Key Laboratory for Biomedical Effects of Nanomaterials and Nanosafety, Institute of High Energy Physics, Chinese Academy of Sciences, Beijing 100049, China; ${ }^{4}$ University of Chinese Academy of Sciences, Beijing 100049, China; ${ }^{5}$ Southwest Eye Hospital/Southwest Hospital, Third Military Medical University, Chongqing 400038, China

*These authors contributed equally to this work

Correspondence: Jingci Zhu School of Nursing,Third Military Medical University, 30 Gaotanyan Street, Shapingba District, Chongqing 400038, China

Tel +86236877 I839

Email zhujingci2009@163.com

Xiaotang Fan

Department of Developmental Neuropsychology, School of Psychology,

Third Military Medical University, 30

Gaotanyan Street, Shapingba District,

Chongqing 400038, China

Tel +86236877 I78I

Email fanxiaotang2005@I63.com
Introduction: Silica nanoparticles $\left(\mathrm{SiO}_{2}-\mathrm{NPs}\right)$ are currently among the most widely used nanomaterials, but their potentially adverse effects on brain development remain unknown. The developing brain is extremely sensitive to NP neurotoxicity during the early postnatal period. Materials and methods: Herein, we investigated the effects of $\mathrm{SiO}_{2}-\mathrm{NPs}$ (doses of 10, 20, or $50 \mathrm{mg}$ with a particle size of $\sim 91 \mathrm{~nm}$, equivalent to aerosol mass concentrations 55.56, 111.11, and $277.78 \mathrm{mg} / \mathrm{m}^{3}$, respectively) exposure from postnatal day (P) 1 to $\mathrm{P} 7$ on hippocampal precursor proliferation at $\mathrm{P} 8$ and long-term neurobehavior in adults.

Results: $\mathrm{SiO}_{2}$-NP exposure resulted in inflammatory cell infiltration in lung tissue, microglia over-activation in the hippocampal dentate gyrus (DG), and decreased hippocampal precursor proliferation in the DG-subgranular zone at P8. Moreover, after exposure to $20 \mathrm{mg}$ of $\mathrm{SiO}_{2}-$ NPs, mice exhibited social interaction deficits and slight anxiety-like behaviors in adulthood, but this exposure did not induce locomotor activity impairment, depression-like behavior, or short-term memory impairment.

Discussion: These findings suggest that early-age $\mathrm{SiO}_{2}-\mathrm{NP}$ exposure induced inflammation and inhibited precursor proliferation in the DG in a dose-dependent manner, which might be related to the social dysfunction observed in adulthood.

Keywords: silica nanoparticles, nanotoxicity, hippocampal neurogenesis, neuroinflammation, social behavior

\section{Introduction}

Silica nanoparticles $\left(\mathrm{SiO}_{2}-\mathrm{NPs}\right)$ are among the most common nanomaterials used and possess particular physicochemical characteristics, such as outstanding chemical stability, strong modifications, and increased surface-to-volume ratios. These NPs are widely used in cosmetics, medicine, chemical engineering, and food production. ${ }^{1}$ In the past decades, the widespread use of NPs has indeed made our lives much more convenient. However, more than $\sim 1.5$ million tons of $\mathrm{SiO}_{2}-\mathrm{NPs}$ have been produced in the world per year. ${ }^{2}$ The release of these NPs into the environment, especially the atmosphere, may contribute to the problem of haze and can be detrimental to human health. Therefore, it is a pressing challenge to assess the biological effects related to the exposure of $\mathrm{SiO}_{2}$-NPs.

NPs have the propensity to enter through the airway and skin and have unconstrained access to the main organs, including the kidneys, liver, spleen, brain, and lungs. ${ }^{3}$ It has been well demonstrated that the inhaled NPs initiate a sustained inflammatory response in lungs. Moreover, recent studies have documented that the brain may be a potential target for these NPs. ${ }^{4}$ In vitro studies have widely confirmed that 
NPs elicit toxic effects on neurons and glia. ${ }^{5,6}$ A substantial amount of evidence has also demonstrated that NPs can cross the blood-brain barrier (BBB) and enter the brain to elicit further cytotoxicity. ${ }^{7,8}$ Therefore, it is critical to assess the potential neurotoxic effects of NPs on brain function.

The hippocampus is involved in cognitive processes, such as learning and memory, ${ }^{9}$ and is also extremely vulnerable to inflammatory injury. Several lines of evidence suggest that the hippocampus is heavily affected by $\mathrm{SiO}_{2}-\mathrm{NPs}$. The intranasal instillation of $\mathrm{SiO}_{2}$-NPs for 30 days has been found to result in a significant increase in the silica content of the hippocampus that leads to immune and inflammatory responses and increased expressions of pro-inflammatory cytokines and chemokines. ${ }^{10}$ Additionally, $70 \mathrm{~nm} \mathrm{SiO} 2$-NPs have been observed in the cerebral cortex and hippocampus after dermal exposure for 28 days. ${ }^{11}$ One recent study indicated that $\mathrm{SiO}_{2}-\mathrm{NPs}$ can disturb the $\mathrm{BBB}$ structure and function to induce BBB inflammation. ${ }^{12}$ Nanosized materials seem to penetrate into neonatal brains with more ease; at this stage, the permeability of the BBB is high. Thus, following their entrance into the neonatal brain via the BBB, NPs lead to the secretion of inflammatory cytokines that will induce severe pathological consequences in the developing brain and lead to neurobehavioral deficits in adults. Although many studies have been conducted to investigate the effects of $\mathrm{SiO}_{2}-\mathrm{NPs}$, their developmental effects in the brain have not yet been fully examined.

In the present study, we evaluated whether $\mathrm{SiO}_{2}-\mathrm{NP}$ exposure in neonatal mice from postnatal day (P) 1 to $\mathrm{P} 7$ induced inflammation in the lungs and brain. We sought to determine whether early life $\mathrm{SiO}_{2}$-NP exposure could produce aberrant hippocampal neurogenesis, including abnormal proliferation of neural progenitor cells (NPCs) and abnormal maintenance of NPCs. We also elucidated the long-term consequences for social behavior, learning and memory abilities, and anxietylike or depressive-like behaviors. This study provides a more comprehensive understanding of the neurotoxic effects of $\mathrm{SiO}_{2}-\mathrm{NP}$ exposure on the function of the developing brain.

\section{Materials and methods Reagents for $\mathrm{SiO}_{2}-\mathrm{NPs}$}

Fluorescein isothiocyanate (FITC, 95\%), 3-aminopropyltriethoxysilane (APTES, 98\%), tetraethyl orthosilicate (TEOS, $98 \%$ ), and ammonium hydroxide $\left(\mathrm{NH}_{4} \mathrm{OH}, 28 \%-30 \%\right.$ as $\mathrm{NH}_{3}$ ) were purchased from Alfa Aesar Ltd (Shanghai, China). Absolute ethyl alcohol was acquired from the Beijing Chemical Reagent Company (Beijing, China). All materials were used as received and without further purification. Purified water was used throughout.

\section{Synthesis and characterization of $\mathrm{SiO}_{2}-\mathrm{NPs}$}

FITC labeled $\mathrm{SiO}_{2}$-NPs were prepared via a previously described method. ${ }^{13}$ Briefly, FITC-APTES precursor solution was prepared in advance and added to a mixture containing $40 \mathrm{~mL}$ ethanol, $5 \mathrm{~mL}$ TEOS, and $5 \mathrm{~mL}$ deionized water in a $250 \mathrm{~mL}$ flask. Afterward, $1 \mathrm{~mL}$ ammonium hydroxide dispersed in $10 \mathrm{~mL}$ ethanol was added dropwise, and the mixture was stirred at room temperature in a dark place. Then, the mixed solution was centrifuged and washed with ethanol and water several times to remove free FITC-APTES and ammonium ions. The synthesized FITC-modified $\mathrm{SiO}_{2}-\mathrm{NPs}$ were freeze-dried and stored in a dark place for further use.

The scanning electron microscope images of $\mathrm{SiO}_{2}-\mathrm{NPs}$ were taken on S-4800 (Hitachi, Tokyo, Japan). The size distribution and zeta potential of the samples were measured with a NanoBrook ZetaPlus (Brookhaven, New York, NY, USA). The green fluorescence of the as-synthesized $\mathrm{SiO}_{2}$ nanopowders was observed under ultraviolet illumination (365 nm wavelength).

\section{Animals}

Pregnant C57/BL6 mice were provided by the Third Military Medical University. The animals were maintained in an environment with standardized room temperature, a 12-hour light/12-hour dark cycle, and ad libitum access to food and water. Except for the brief intervals of separation required for daily exposure, the postnatal pups stayed with their mothers during the experimental periods.

\section{Inhalation exposure}

The whole-body animal inhalation exposure system was used in the study (Figure S1). The exposure chamber with air outlets to keep the pressure constant was connected to the atomizer (Pari Boy SX; Pari GmbH, Starnberg, Germany). Before exposure, $\mathrm{SiO}_{2}$-NP suspensions were made with different doses of $\mathrm{SiO}_{2}-\mathrm{NPs}(10 \mathrm{mg}, 20 \mathrm{mg}$, and $50 \mathrm{mg})$ dispersed in $3 \mathrm{~mL}$ of saline and subsequently ultrasonicated for $1 \mathrm{~h}$ to avoid any possible agglomerates. A vortex turbulence instrument (Qilinbeier, Jiangsu, China) was then used for 5 min to keep the $\mathrm{SiO}_{2}$-NPs spread evenly in the saline. Then, previously prepared $\mathrm{SiO}_{2}$-NP suspensions were delivered by the nebulizer with compressed particle-free air at atomization speed of $0.1 \mathrm{~mL} / \mathrm{min}$. Control groups were exposed to filtered air with solution ( $3 \mathrm{~mL}$ saline). Typical air flow rate through the chamber was $\sim 6 \mathrm{~L} / \mathrm{min}$ with a corresponding exposure time of $30 \mathrm{~min}$. Briefly, the estimated mass concentration of $\mathrm{SiO}_{2}-\mathrm{NP}$ aerosol was $55.56 \mathrm{mg} / \mathrm{m}^{3}$ for $10 \mathrm{mg} \mathrm{SiO}{ }_{2}-\mathrm{NP}$ treatment group, $111.11 \mathrm{mg} / \mathrm{m}^{3}$ for $20 \mathrm{mg} \mathrm{SiO} \mathrm{S}_{2}-\mathrm{NP}$ treatment

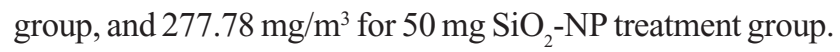


The average particle size of aerosol was about $2.2 \mu \mathrm{m}$, of which more than $75 \%$ were smaller than $5 \mu \mathrm{m}$.

The day of birth was designated as P0. From P1 to P7, pups were aspirated with different doses of $\mathrm{SiO}_{2}-\mathrm{NPs}(10 \mathrm{mg}$, $20 \mathrm{mg}, 50 \mathrm{mg}$, respectively) or filtered air for control (containing $3 \mathrm{~mL}$ of saline) once per day for $30 \mathrm{~min}$. To avoid the litter effect, the animals in each treatment group were randomly chosen from multiple litters. To assess the effect of the $\mathrm{SiO}_{2}$-NPs on cell proliferation in dentate gyrus (DG), pups received 5-bromo-2-deoxyuridine (BrdU) at a dose of $50 \mathrm{mg} / \mathrm{kg}$ per intraperitoneal injection (ip) on P8 and were sacrificed $2 \mathrm{~h}$ after BrdU administration (Figure 1A). To study whether the $\mathrm{SiO}_{2}-\mathrm{NP}$ exposure during the first neonatal week caused behavioral disorder, we choose the same exposure protocol with saline or the $20 \mathrm{mg} \mathrm{SiO}_{2}-\mathrm{NP}$ dose for the subsequent behavioral tests (Figure 1B).

\section{Immunohistochemistry and immunofluorescence}

The brains and lungs (P8) were dissected and fixed in $4 \%$ paraformaldehyde (PFA) for $24 \mathrm{~h}$ at $4^{\circ} \mathrm{C}$. Partial lung samples were embedded in paraffin, sectioned, and stained with hematoxylineosin (HE) for histological examination. The remaining brain and lung samples were post-fixed in a $30 \%$ sucrose solution with $4 \%$ PFA at $4{ }^{\circ} \mathrm{C}$, and cryosections were collected $(30-\mu \mathrm{m}-$ thick sections for the brains and $10-\mu \mathrm{m}$-thick sections for the lungs). Immunohistochemistry was performed according to the methods detailed in our previous study. ${ }^{14}$ In brief, the sections were incubated with the following primary antibodies in $1 \%$ bovine serum albumin (BSA) overnight at $4^{\circ} \mathrm{C}$ : rabbit anti-ionized calcium binding adapter molecule 1 (Iba1, 1:1,000; Wako); mouse anti-BrdU (1:600; BD Biosciences, San Jose, CA, USA); rabbit anti-glial fibrillary acidic protein
(GFAP, 1:200, Dako) and mouse anti-sex-determining region Y (SRY)-box 2 (Sox2, 1:500; Abcam); and 1\% BSA replaced the primary antibody for the negative control. For the BrdU staining, the sections were pretreated with $2 \mathrm{~N} \mathrm{HCl}$ for $0.5 \mathrm{~h}$ at $37^{\circ} \mathrm{C}$ to denature the DNA before the regular immunostaining procedure. After washing, the sections were incubated with biotin-conjugated secondary antibodies and visualized under bright-field microscopy with a diaminobenzidine substrate kit (Zhongshan, Beijing, China). The stained cells were viewed and photographed under a Zeiss Axivert microscope (Oberkochen, Germany) equipped with a Zeiss AxioCam digital color camera connected to the Zeiss AxioVision 3.0 system. For immunofluorescence, the sections were then incubated with $\mathrm{Cy} 3-$ or 488-conjugated (both at 1:400, 3 h; Jackson ImmunoResearch, West Grove, PA, USA) secondary antibodies and mounted in Vectashield (Vector Laboratories, Inc., Burlingame, CA, USA). The nuclei were subsequently stained with 4',6-diamidino-2phenylindole (Beyotime, Shanghai, China). The sections were visualized using a confocal laser-scanning microscope (Leica TCS-SP2, laser lines at 488, 543, 633; Heidelberg, Germany) and analyzed with Leica imaging software.

\section{Real-time quantitative polymerase chain reaction ( $R T-q P C R$ )}

RT-qPCR was performed as previously described. ${ }^{15}$ In brief, total RNA was extracted from the hippocampus using Trizol (Thermo Fisher Scientific, Waltham, MA, USA) and was reverse transcribed according to the manufacturer's instructions. Quantitative PCR was then performed in triplicate with a CFX96 Real-time PCR System (BioRad) using SYBR Green qPCR Mix (Takara Bio Inc., Kusatsu, Japan). Amplification was performed under the following conditions: 1 cycle $\left(30 \mathrm{~s}\right.$ at $\left.95^{\circ} \mathrm{C}\right)$, 40 cycles $\left(5 \mathrm{~s}\right.$ at $95^{\circ} \mathrm{C}, 30 \mathrm{~s}$ at $\left.60^{\circ} \mathrm{C}\right)$ and then storage at $4^{\circ} \mathrm{C}$. The

A

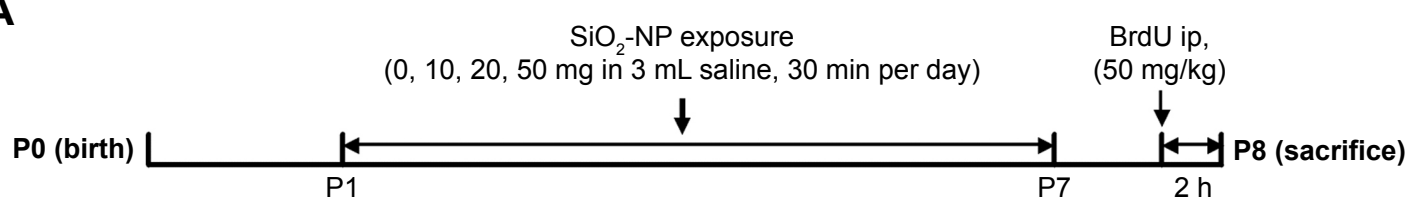

B

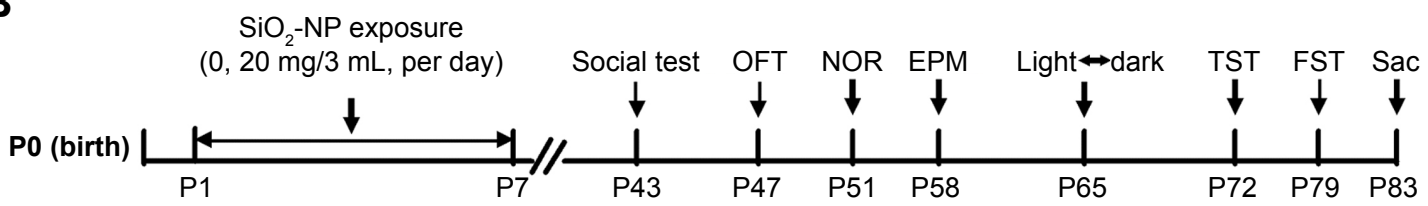

Figure I Schematic diagram of the experimental procedures.

Notes: (A) Mice were exposed to atomized $\mathrm{SiO}_{2}-\mathrm{NPs}$ at different doses (10 mg, $20 \mathrm{mg}$, and $50 \mathrm{mg}$ ) from PI-P7 and then injected with BrdU (50 mg/kg) at P8. Pups were sacrificed $2 \mathrm{~h}$ after BrdU injection, and the brains and lungs were collected for the next experiment. (B) Mice underwent the same process as above at the dose of $20 \mathrm{mg}$ during the first week and returned to normal life until the initiation of the behavior tests.

Abbreviations: $\mathrm{P}$, postnatal day; $\mathrm{SiO}_{2}-\mathrm{NPs}$, silica nanoparticles; BrdU, 5-bromo-2-deoxyuridine; ip, intraperitoneal; OFT, open-field test; NOR, novel object recognition; EPM, elevated plus maze; TST, tail suspension test; FST, forced swimming test; Sac, sacrifice. 
relative expression levels were normalized to the same value of expression as the GAPDH and were calculated using the $2^{-\Delta \Delta C(t)}$ method. All of the primers were purchased from Sangon Biotech and included the following: nuclear factor- $\kappa \mathrm{B}(\mathrm{NF}-\kappa \mathrm{B})$ P65, forward 5'-GCGTACACATTCTGGGGAGT-3' and reverse 5'-ACCGAAGCAGGAGCTATCAA-3'; TNF- $\alpha$, forward 5'-CAAACCACCAAGTGGAGGAG-3' and reverse 5'-GTGGGTGAGGAGCACGTAGT-3'; and GAPDH, forward 5'-AGGTTGTCTCCTGCGACTTCA-3' and reverse 5'-TGGTCCAGGGTTTCTTACTCC-3'.

\section{Behavioral assays}

\section{Three-chamber sociability test}

The three-chamber sociability test was used to determine the sociability and preference for social novelty of mice. As previously reported, ${ }^{16,17}$ the rectangular three-chambered apparatus $(60 \times 40 \times 22 \mathrm{~cm})$ was made from clear polycarbonate and divided into three equal chambers by two clear walls with doorways that allowed access into each chamber. A solution of $70 \%$ alcohol and water was used to clean the chambers at the end of each test to prevent olfactory stimulation. The task consisted of three 10-minute long phases. In the first phase, mice were permitted to explore three chambers freely for $10 \mathrm{~min}$. In the next phase, a novel mouse (stranger 1) and a novel object were put in the two sides of chamber. Mice were then allowed to explore the three chambers again for $10 \mathrm{~min}$. In the last phase, the novel object was replaced with another novel mouse (stranger 2). Mice were allowed to explore the chambers for another $10 \mathrm{~min}$. On the previous day, the novel mouse was habituated to the plastic cage for $30 \mathrm{~min}$. Noldus Observer software (Ethovision 11.0; Noldus, Wageningen, the Netherlands) was used to analyze the duration in each chamber. Additionally, preference indices, which represented the numerical difference between the time in the chambers (stranger 1 vs object or stranger 2 vs stranger 1) divided by total time, were also calculated.

\section{Open-field test (OFT)}

General exploratory locomotion in a novel open-field environment was assessed according to the methods in our previous study. ${ }^{16}$ The observation cage consisted of a square gray Plexiglas arena $(40 \times 40 \times 30 \mathrm{~cm})$. The floor of the arena was divided into 16 equal squares. A mouse was placed in the center of the floor at the beginning of our test. A video camera was used to record the movement of the mouse for $30 \mathrm{~min}$. The total distance traveled in the apparatus (as a measure of locomotor activity) and the time spent in the central zone (as a measure of anxiety-like behavior) were assessed with Ethovision 11.0 (Noldus).

\section{Novel object recognition (NOR)}

To evaluate short-term memory, the NOR test was conducted according to a previous method with minor modification. ${ }^{18}$ Because mice have an innate preference for novelty, if the mouse recognizes the familiar object, it will spend most of its time at the novel object. ${ }^{19}$ Briefly, mice were individually habituated to a square gray Plexiglas arena $(40 \times 40 \times 30 \mathrm{~cm})$ for $10 \mathrm{~min}$ in the first phase. In the second phase, mice were placed in the same arena containing two identical objects (familiarization phase) and allowed to explore freely for $10 \mathrm{~min}$. In the last phase, one of the familiar objects was replaced with a new one. The time exploring each object was recorded during this phase and an exploratory preference index (the time spent exploring the new object divided by total time spent with both objects $\times 100 \%$ ) was calculated. The individual movement tracks were analyzed with Ethovision 11.0 (Noldus).

\section{Elevated plus maze (EPM)}

The EPM test was conducted to measure the level of anxiety in the rodents. ${ }^{20,21}$ The maze was comprised of two open arms $(30 \times 6 \times 15 \mathrm{~cm})$, two closed arms $(30 \times 6 \times 15 \mathrm{~cm})$, and a central area $(6 \times 6 \mathrm{~cm})$. Briefly, mice were placed at the center of the maze facing an open arm and allowed to explore for $5 \mathrm{~min}$. The mouse's entry into any of the four arms was counted when all four paws crossed from the central region into an arm. The percentage of time spent in the open arms and the percentage of open arm entries were recorded with Noldus Observer software (Ethovision 11.0). The anxiety-prone mice tend to avoid the open arms of the plus maze. Lower percentages indicate more anxiety reactivity.

\section{Light $\leftrightarrow$ dark transitions}

The light $\leftrightarrow$ dark transitions test was conducted as previously described to assess anxiety-like conflict behavior in mice. ${ }^{21,22}$ Initially, mice were placed into the brightly lit compartment ( 400 lux; $20 \times 15 \times 25 \mathrm{~cm}$; facing away from the opening) and allowed to explore freely between the light and dark chambers $(20 \times 15 \times 25 \mathrm{~cm})$ for $10 \mathrm{~min}$. The time spent in the light side chamber and the total transitions between the two sides of the chamber were automatically recorded using Noldus Observer software (Ethovision 11.0) and considered indices of anxiety and overall activity, respectively.

\section{Forced swimming test (FST)}

The FST was performed as described earlier. ${ }^{23}$ Briefly, mice were individually placed in glass cylinders (height: $20 \mathrm{~cm}$, diameter: $10 \mathrm{~cm})$ containing $10 \mathrm{~cm}$ height of water $\left(23^{\circ} \mathrm{C} \pm 1^{\circ} \mathrm{C}\right)$. When the mouse remained floating in the water in an upright 
position without struggling or exhibited only the movement necessary to keep their heads above water, we deemed them immobile. The immobility durations during the last $4 \mathrm{~min}$ of the total of 6 min were obtained by two operators.

\section{Tail suspension test (TST)}

The TST was performed according to previously reported methods. ${ }^{24,25}$ Mice were suspended by a mounted hook $50 \mathrm{~cm}$ above the floor using adhesive tape, which was placed $\sim 1 \mathrm{~cm}$ from the tip of the tail. The activities of mice were recorded for $6 \mathrm{~min}$. The immobility duration was evaluated during the last $4 \mathrm{~min}$.

\section{Quantification}

Stereological quantification of $\mathrm{BrdU}^{+}$cells in the DG The total number of BrdU-positive cells in the DG was quantified using stereological cell counting according to our previous method. ${ }^{14}$ Briefly, serial $30 \mu \mathrm{m}$ sections through the rostrocaudal extent of the DG were selected in 10-section intervals. The total sum of the BrdU-positive cells traced was multiplied by BrdU-positive cells in the DG (granule cell layer [GCL] plus subgranular zone [SGZ] and hilus) per section and series number to give the total number of BrdU-positive cells in the DG. Five animals per group were used for analysis.

\section{Determination of $\mathrm{Ibal}^{+}$, So $2^{+}$, So $\times 2^{+} / \mathrm{GFAP}^{+}$cells in the DG}

Radial glial cells (RGCs) were immunofluorescently doublestained with Sox $2 /$ GFAP. The somata of the radial glia have a triangular shape with processes that are marked by GFAP and usually project toward the molecular layer. The number of

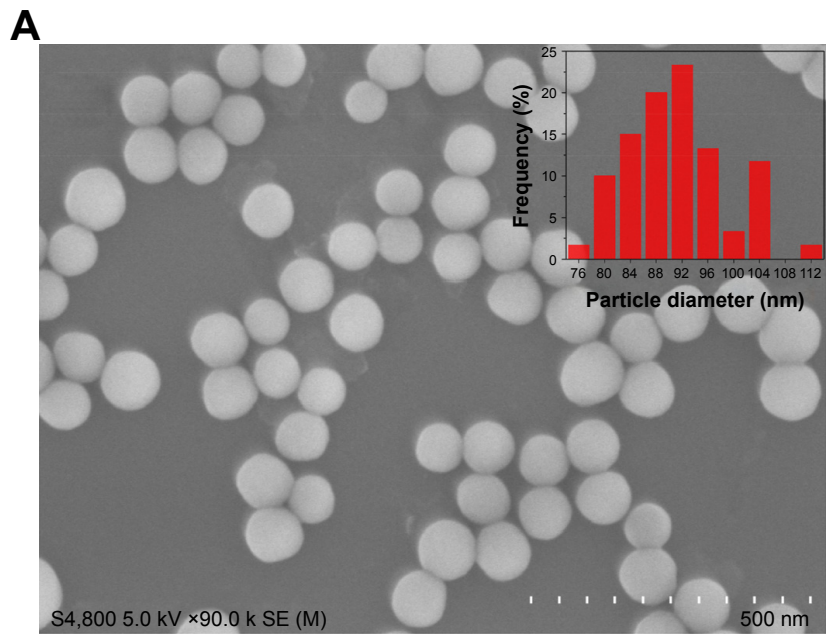

$\mathrm{Iba}^{+}, \mathrm{Sox}^{+}$, and $\mathrm{Sox}_{2} / \mathrm{GFAP}^{+}$cells in the GCL (plus SGZ) of five matched sections per animal were counted, and the average value of a section was determined for each animal. Five animals per group were used for the analysis.

\section{Statistical analyses}

All data are presented as the mean \pm SEM with at least five replicates per group. Immunohistochemistry data were analyzed using one-way analysis of variance followed by Fisher's least significant difference post hoc test for multiple comparisons (SPSS 22.0; IBM Corporation, Armonk, NY, USA). Unpaired $t$-tests between groups were used to evaluate the results of the EPM, FST, TST, and NOR tests. For the body weight analysis, three-chamber sociability test, the total distance and center time in the OFT, repeated-measures analyses of variance (paired $t$-tests) were employed to compare the between-group factor of dose and the within-group factor of time (body weight analysis and OFT) or chamber (three-chamber sociability test). For all comparisons, the significance level was set at $p<0.05$.

\section{Ethics approval and informed consent}

All experimental procedures were approved by Third Military Medical University and were performed according to the guidelines of laboratory animal care and use.

\section{Results \\ Characteristics of the $\mathrm{SiO}_{2}-\mathrm{NPs}$}

The average diameter of the as-obtained $\mathrm{SiO}_{2}-\mathrm{NPs}$ was $\sim 91 \mathrm{~nm}$ under scanning electron microscope (Figure 2A), which was smaller than the hydrodynamic diameter $(\sim 130 \mathrm{~nm}$, dynamic light scattering, Figure 2B) in water due to better water dispersibility. Additionally, the zeta potential of the $\mathrm{SiO}_{2}-\mathrm{NPs}$ in

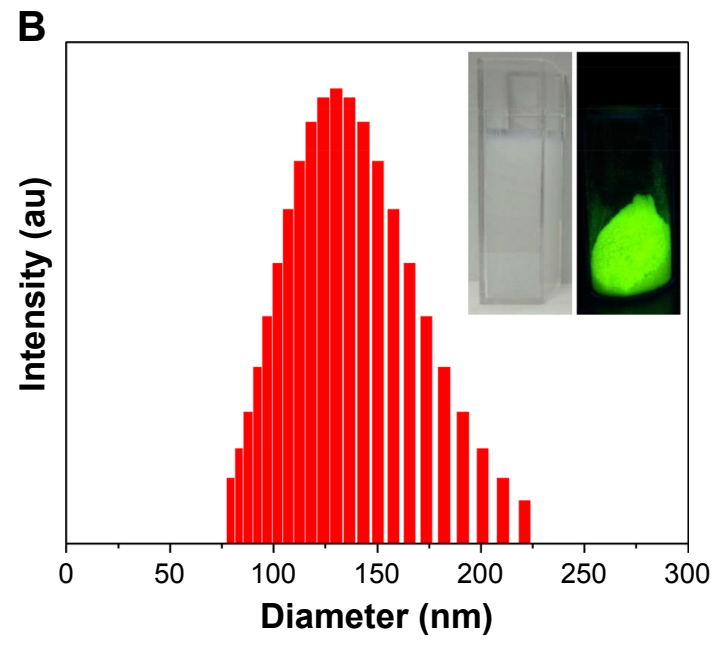

Figure 2 Characterization of the FITC-labeled $\mathrm{SiO}_{2}-\mathrm{NPs}$.

Notes: (A) Scanning electron microscope images of $\mathrm{SiO}_{2}-\mathrm{NPs}$ and the corresponding size distribution plot (inset). (B) Diameter distribution of the $\mathrm{FITC}$-labeled $\mathrm{SiO}{ }_{2}-\mathrm{NPs}$ in purified water as assessed by dynamic light scattering. Inset: dispersion in water (left) and fluorescent photograph of $\mathrm{FITC}_{\mathrm{T}}$ labeled $\mathrm{SiO}_{2}-\mathrm{NPs}$ (right).

Abbreviations: $\mathrm{SiO}_{2}-\mathrm{NPs}$, silica nanoparticles; FITC, fluorescein isothiocyanate. 
water was approximately $-36.19 \mathrm{mV}$. The bright green fluorescence under ultraviolet illumination (inset in Figure 2B) indicated the successful conjugation of FITC on the surfaces of the $\mathrm{SiO}_{2}$-NPs.

\section{Exposure to $\mathrm{SiO}_{2}-\mathrm{NPs}$ did not alter the average body or brain weight}

The body weights of pups from all four groups were recorded from P1 to P8. There was no effect on the treatment group $(F[3,36]=0.344 ; p=0.793)$. The average body weight of mice in the control group was slightly higher (but not significantly) than that of those treated with the $\mathrm{SiO}_{2}$-NPs (Figure 3A). Moreover, there was no significant difference in mean brain weight between the four groups on P8 (Figure 3B).

\section{Exposure to $\mathrm{SiO}_{2}-\mathrm{NPs}$ induced inflammatory response in the lungs of the 8-day-old mice}

Light microscopy micrographs of HE-stained tissues depicted the onset of histopathological changes in the lung architecture (Figure 3C-J). HE staining revealed that the morphologies of the alveoli were similar among the four groups. However, $\mathrm{SiO}_{2}-\mathrm{NP}$ exposure induced inflammatory cell infiltration compared with the control group. Additionally, in all nanoparticle exposed animals, increased numbers of diffusely scattered macrophages accumulated with FITC-labeled $\mathrm{SiO}_{2}-$ NPs were observed within alveoli, when detected under an immunofluorescent microscope (Figure $3 \mathrm{~K}-\mathrm{R}$ ).

\section{$\mathrm{SiO}_{2}-\mathrm{NP}$ exposure induced over- activation of microglia in the DG and a hippocampal inflammatory response}

Iba-1 was selected to trace the activation of microglia. In Figure 4A-H, the microglia cells exhibited smaller cell bodies with fewer and scattered processes in the DGs of the saline-treated control mice. However, enlarged cell bodies with thicker and more condensed processes were present in the DGs of the different $\mathrm{SiO}_{2}$-NP-treated mice. Additionally, the number of microglia labeled by Ibal increased greatly in the DGs of the neonatal mice following $\mathrm{SiO}_{2}-\mathrm{NP}$ exposure (Figure 4I) compared with the control pups. RT-qPCR also revealed that the mRNA expressions of inflammation-related genes, such as TNF- $\alpha$ and NF- $\kappa$ B P65, were significantly higher in the $\mathrm{SiO}_{2}-\mathrm{NP}$-treated pups than in the control group (Figure 4J and K). These data suggest that the inhalation of $\mathrm{SiO}_{2}$-NPs may directly induce hippocampal over-activation of microglia and an inflammatory response in newborn mice at P8.
$\mathrm{SiO}_{2}-\mathrm{NP}$ exposure inhibited $\mathrm{BrdU}$-labeled cell proliferation in the DG in a dosedependent manner

As illustrated in Figure 5, $2 \mathrm{~h}$ after BrdU administration at P8, the most intense BrdU labeling of the cells was localized in the GCL and hilus. There was no difference in the BrdU-positive cells in the DG between pups that were treated

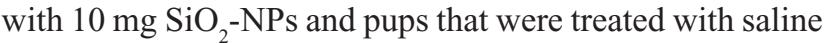
$(p>0.05)$. However, the BrdU-positive cells in the DG were significantly decreased in the higher-dose $\mathrm{SiO}_{2}$-NP treatment groups (20 mg and $50 \mathrm{mg}$ ) compared with the control pups per DG $\left(8,070 \pm 174.642\right.$, vehicle vs 7,476 $\pm 184.000 \mathrm{SiO}_{2}-\mathrm{NPs}$ $20 \mathrm{mg}, p<0.05 ; 8,070 \pm 174.642$ vehicle vs $6,844 \pm 216.046$ $\mathrm{SiO}_{2}$-NPs $50 \mathrm{mg}, p<0.001$ ). These data indicated that $\mathrm{SiO}_{2}-$ NPs at higher doses could significantly inhibit the proliferation of NPCs in the hippocampal DGs of neonatal mice.

\section{$\mathrm{SiO}_{2}-\mathrm{NP}$ exposure exhausted the NPC pool in the DGs of 8-day-old mice}

To assess the effects of $\mathrm{SiO}_{2}-\mathrm{NPs}$ on the NPCs in the DGs of newborn mice, we analyzed the number of Sox2labeled NPCs among the four groups. Compared to the vehicle-treated group, $\mathrm{SiO}_{2}$-NP-treated mice exhibited lower number of Sox $2^{+}$neural stem/early progenitor cells in the GCL (Figure 6A-I). Postnatally, RGCs act as neurogenic progenitors that give rise to subsequent NPCs. To further explore the defects in the NPC pool in mice treated with $\mathrm{SiO}_{2}$-NPs, we determined the number of RGCs with Sox2 and GFAP double-staining method. Indeed, $\mathrm{SiO}_{2}-\mathrm{NP}$ exposure significantly decreased the pool of NPCs in the DG at P8 compared with the vehicle-treated group as measured by the cells with radial glial morphology and the expressions of both GFAP and Sox2 (Figure 6A-H and J). These findings indicated that the decrease in cellular proliferation in the hippocampus induced by $\mathrm{SiO}_{2}-\mathrm{NPs}$ exposure may be due to a decline in the number of stem/progenitor cells available in the GCL.

\section{$\mathrm{SiO}_{2}-\mathrm{NP}$-treated mice exhibited reduced social novelty preference in the three- chamber sociability test}

We examined whether $\mathrm{SiO}_{2}-\mathrm{NP}$ exposure could alter social interaction in mice with the three-chamber paradigm test. In the sociability test stage (Figure 7A and B), the preference of a mouse for a stranger mouse versus a novel inanimate object is compared. Although only vehicle-treated mice interacted more with the mouse than with an empty enclosure (Figure 7E), the mean preference index of $\mathrm{SiO}_{2}-\mathrm{NP}$-treated 
A

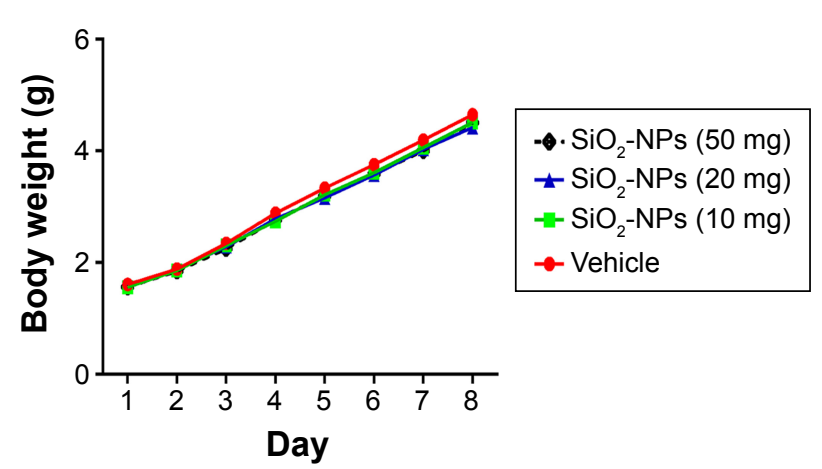

B

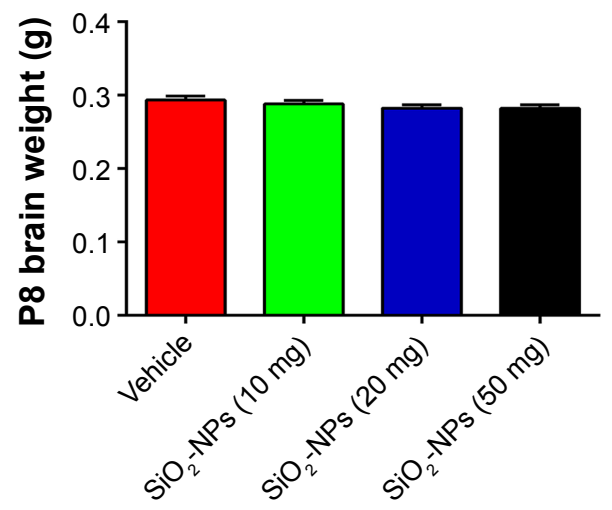

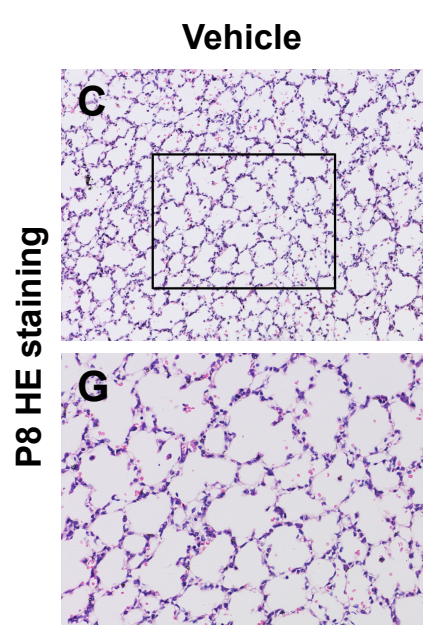

$\mathrm{SiO}_{2}$-NPs $(10 \mathrm{mg})$

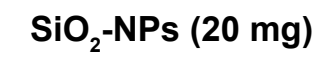

$\mathrm{SiO}_{2}-\mathrm{NPs}(50 \mathrm{mg})$
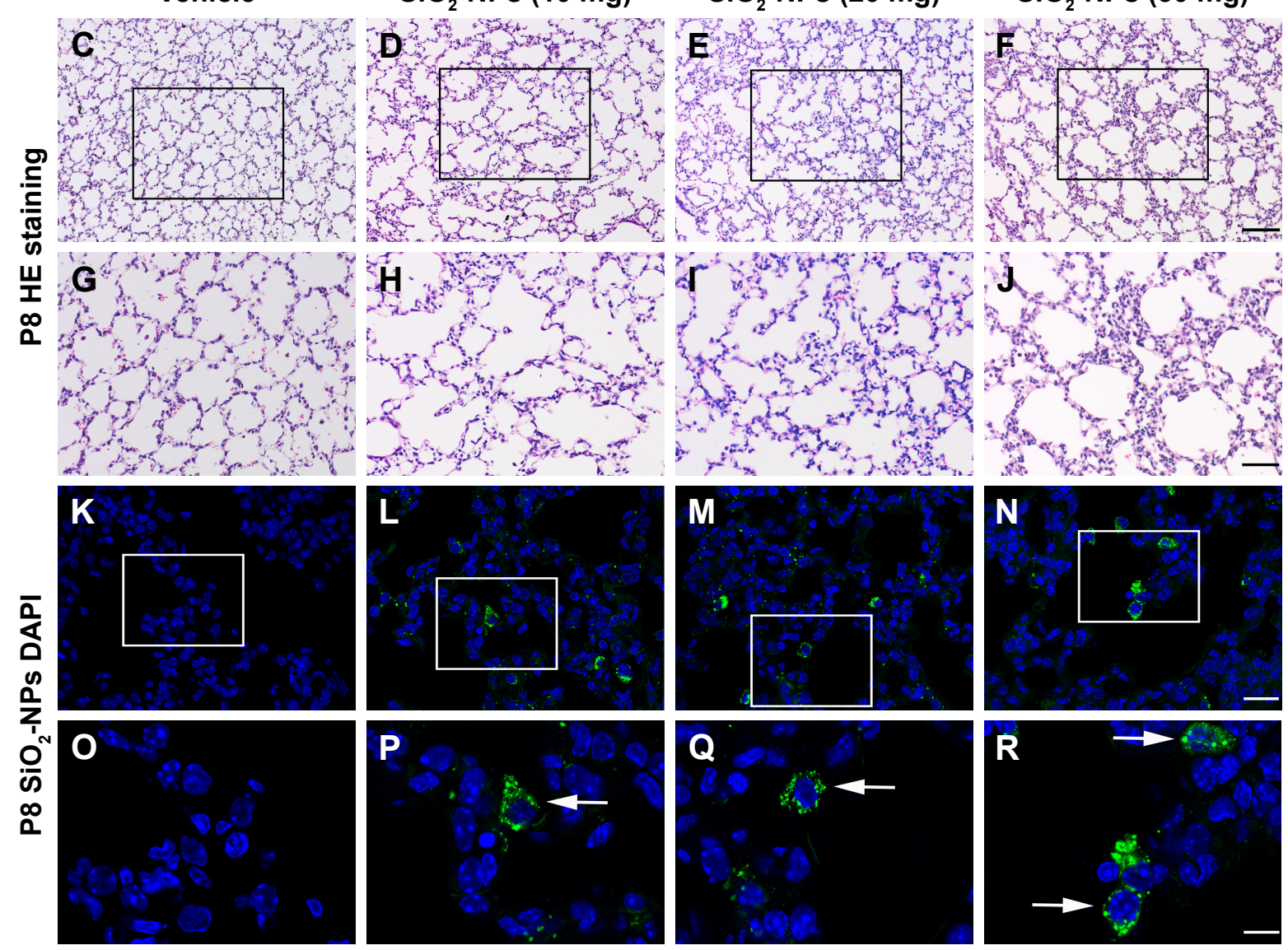

Figure $3 \mathrm{SiO}_{2}-\mathrm{NP}$ treatment induced inflammatory response in the lungs of the 8-day-old mice without alteration in the body and brain weight.

Notes: (A) The effects of $\mathrm{SiO}_{2}-\mathrm{NP}$ exposure on the average body weights of mice ( $\mathrm{n}=10$ per group). (B) The effects of $\mathrm{SiO}-\mathrm{NP}$ exposure on brain weight at P8 ( $\mathrm{n}=8$ per group). The data are presented as the mean $\pm \mathrm{SEM}$. (C-F) The structure of the lung as illustrated by $\mathrm{HE}$ staining for the groups: Vehicle, $\mathrm{SiO}{ }_{2}-\mathrm{NPs}$ (I0 mg), SiO $-\mathrm{NPs}(20 \mathrm{mg})$, and $\mathrm{SiO}_{2}-\mathrm{NPs}(50 \mathrm{mg})$. (G-J) The images are higher-power views of $\mathbf{C}-\mathbf{F}$. (K-N) The locations of the $\mathrm{SiO}_{2}-\mathrm{NPs}$ labeled by FITC as revealed by immunofluorescent staining in the four groups: Vehicle, $\mathrm{SiO}_{2}-\mathrm{NPs}(10 \mathrm{mg}), \mathrm{SiO}_{2}-\mathrm{NPs}(20 \mathrm{mg})$, and $\mathrm{SiO}_{2}-\mathrm{NPs}(50 \mathrm{mg})$. (O-R) The images are higher-power views of $\mathbf{K}-\mathbf{N}$. Arrows highlight the FITC-labeled $\mathrm{SiO}_{2}-\mathrm{NP}$ burden observed in alveolar macrophages. The scale bar in $\mathbf{F}=100 \mu \mathrm{m}$ and applies to $\mathbf{C}-\mathbf{F}$; in $\mathbf{J}$ the scale bar $=50 \mu \mathrm{m}$ and applies to $\mathbf{G}-\mathbf{J}$; in $\mathbf{N}$ the scale bar $=25 \mu \mathrm{m}$ and applies to $\mathbf{K}-\mathbf{N}$; and in $\mathbf{R}$ the scale bar $=10 \mu \mathrm{m}$ and applies to $\mathbf{O}-\mathbf{R}$.

Abbreviations: $\mathrm{SiO}_{2}-\mathrm{NPs}$, silica nanoparticles; FITC, fluorescein isothiocyanate; SEM, standard error of the mean; DAPI, 4',6-diamidino-2-phenylindole.

mice was compatible with those in vehicle-treated mice (Figure 7G). Additionally, measurements of the preference for a previously encountered familiar mouse versus a new stranger mouse revealed that $\mathrm{SiO}_{2}-\mathrm{NP}$-treated mice
(Figure 7D) displayed a reduced level of social novelty recognition than vehicle-treated mice (Figure 7C) as measured by the time spent in the target (Figure $7 \mathrm{~F}$ ) and the social preference index (Figure $7 \mathrm{H}$ ). Thus, $\mathrm{SiO}_{2}$-NP-treated mice 

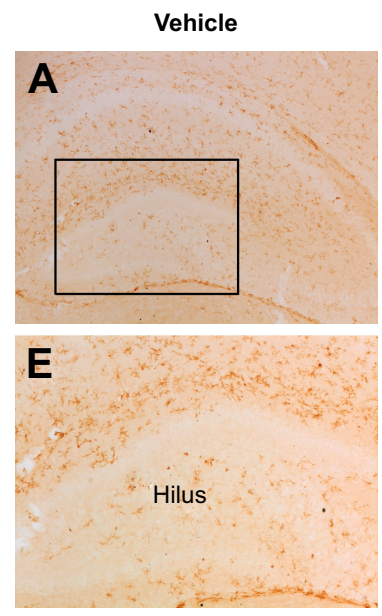

\section{I}

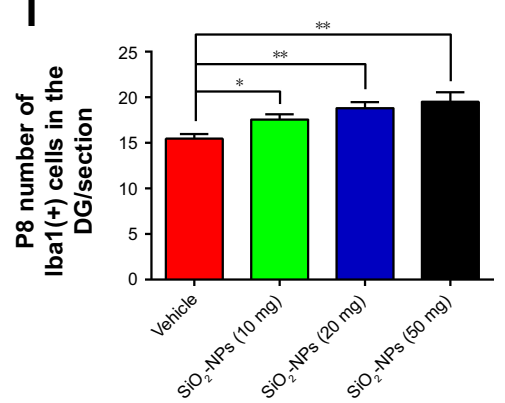

$\mathrm{SiO}_{2}$-NPs $(10 \mathrm{mg})$
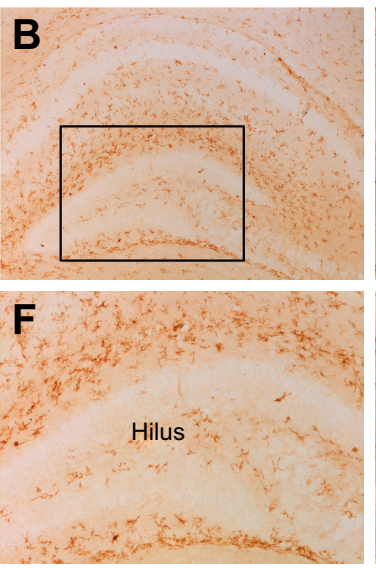

$J$

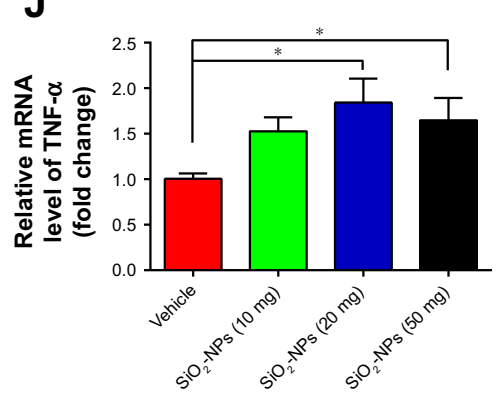

$\mathrm{SiO}_{2}-\mathrm{NPs}(20 \mathrm{mg})$
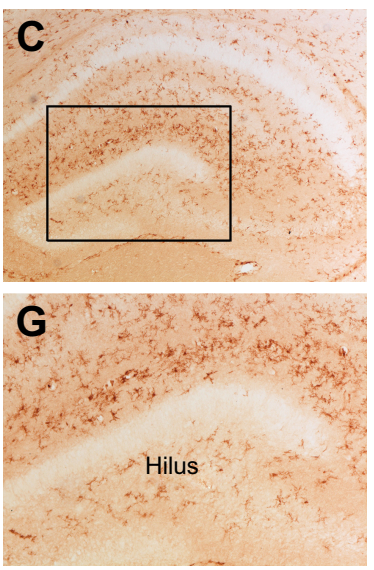

K

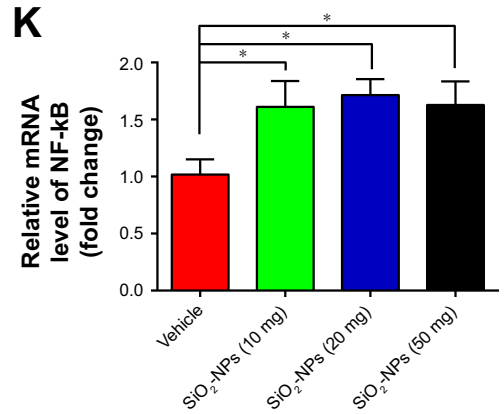

Figure $4 \mathrm{SiO}_{2}$-NP treatment induced over-activation of microglia in the DG and a hippocampal inflammatory response.

Notes: (A-D) Microglia cells labeled by lbal in the DGs of the different groups. (E-H) Higher-power views of the boxed areas in A-D. (I) Quantitative analysis of the number of $\mathrm{Ibal}^{+}$cells in the DG. ( $\mathrm{J}$ and $\mathbf{K}$ ) Relative mRNA expressions of TNF- $\alpha$ and NF-KB P65. The data are presented as the mean \pm SEM ( $\mathrm{n}=5$ for immunohistochemistry, $\mathrm{n}=3$ for RT-qPCR). ${ }^{*} p<0.05$, ${ }^{*} p<0.01$. Scale bar in $\mathbf{D}=200 \mu \mathrm{m}$ and applies to $\mathbf{A}-\mathbf{D}$, in $\mathbf{H}=100 \mu \mathrm{m}$ and applies to $\mathbf{E}-\mathbf{H}$.

Abbreviations: $\mathrm{SiO}_{2}-\mathrm{NPs}$, silica nanoparticles; DG, dentate gyrus; Iba I, ionized calcium binding adapter molecule I; NF- $\kappa B$, nuclear factor- $\kappa \mathrm{B}$; TNF- $\alpha$, tumor necrosis factor alpha; SEM, standard error of the mean; RT-qPCR, real-time quantitative polymerase chain reaction.

exhibited less social novelty preference in the three-chamber sociability test compared with vehicle-treated mice.

\section{$\mathrm{SiO}_{2}-\mathrm{NP}$-treated mice showed no obvious impairments on short-term memory}

To evaluate the effects of $\mathrm{SiO}_{2}-\mathrm{NP}$ exposure on the short-term memories of mice, we conducted the novel object recognition test (Figure 8). $\mathrm{SiO}_{2}-\mathrm{NP}$ exposure did not change the exploratory preference index between groups $(47.461 \% \pm 2.978 \%$ for $\mathrm{SiO}_{2}$-NP-treated mice vs $53.032 \% \pm 2.919 \%$ for salinetreated mice, $p=0.202$, Figure $8 \mathrm{D}$ ). Moreover, there were no group differences in the total exploratory times for all objects (Figure 8C), which indicated that the results were not influenced by potential changes in overall activity.

\section{Effects of $\mathrm{SiO}_{2}-\mathrm{NP}$ exposure on locomotion and anxiety-like and depressive-like behaviors}

To determine whether $\mathrm{SiO}_{2}$-NP exposure affected the overall locomotor activity, the OFT was utilized. The time course of the total distance traversed by mice in the novel open-field chamber over a 30-minute time period significantly decreased (Figure 9A, $F(5,18)=11.253 ; p<0.001$ ), indicating that both groups habituated normally to the chamber. $\mathrm{SiO}_{2}-\mathrm{NP}$ exposure did not significantly alter the total distance traveled when compared to vehicle-treated mice (Figure 9B, $p>0.05$ ). Additionally, we found no difference in $\mathrm{SiO}_{2}$-NP-treated mice in the time spent in the center (Figure $9 \mathrm{C}$ and $\mathrm{D}, p>0.05$ ). This finding indicated that a dose of $20 \mathrm{mg} \mathrm{SiO}_{2}-\mathrm{NP}$ exposure may not elicit an increase in anxiety in the OFT. Two-tailed $t$-tests revealed that the percentage of time in the open arm significantly decreased in $\mathrm{SiO}_{2}$-NP-treated mice compared to control mice (Figure 10A, $p<0.05$ ), and the percentages of entries into open arm were similar between the two groups (Figure 10B, $p>0.05$ ). In the light $\leftrightarrow$ dark transitions test, $\mathrm{SiO}_{2}$-NP-treated mice and mice in the vehicle group exhibited similar times in the light side chamber (Figure 10C, $p>0.05$ ) and similar total transitions (Figure 10D, $p>0.05$ ). The FST and TST were used to analyze depression-like behaviors in mice, and increased immobility is a measure of behavioral despair. As depicted in Figure 10, treatment of mice with 


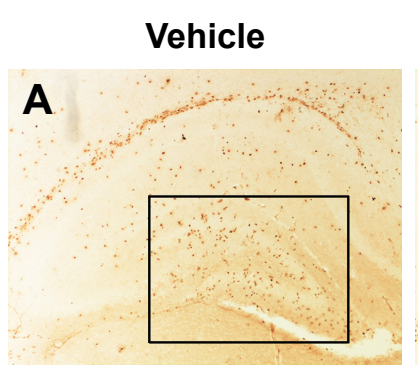

$\mathrm{SiO}_{2}-\mathrm{NPs}(10 \mathrm{mg})$

E

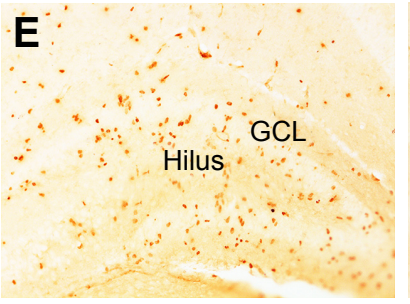

B

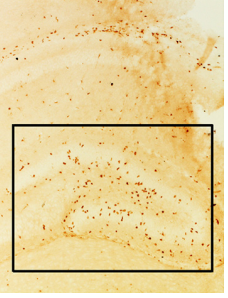

$\mathbf{F}$

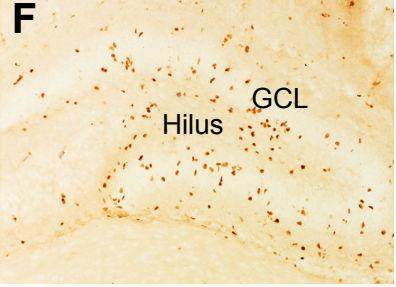

$\mathrm{SiO}_{2}-\mathrm{NPs}(20 \mathrm{mg})$

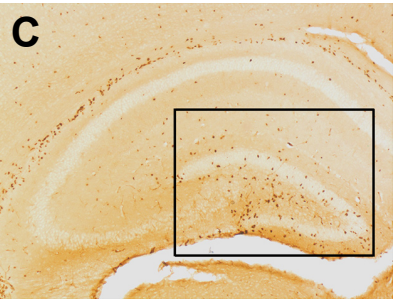

$\mathbf{G}$

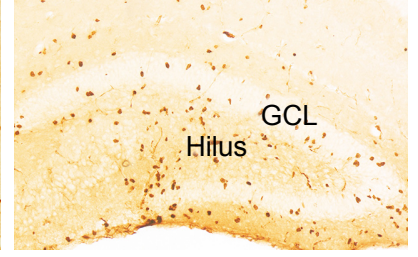

$\mathrm{SiO}_{2}-\mathrm{NPs}(50 \mathrm{mg})$

D

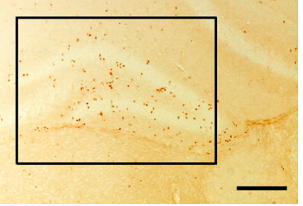

H

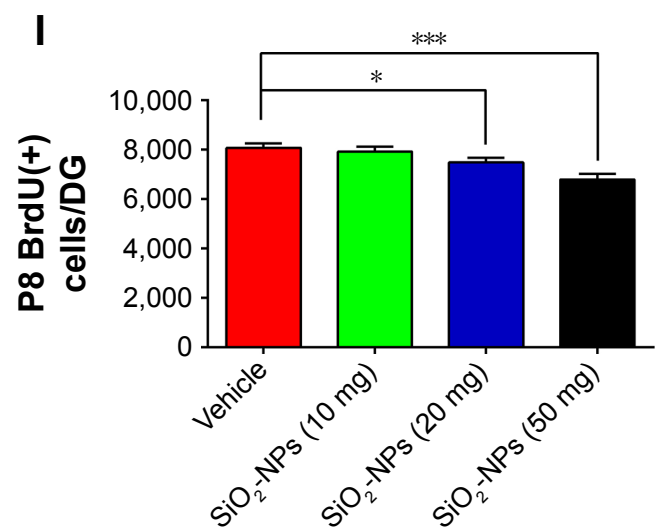

Figure $5 \mathrm{SiO}_{2}-\mathrm{NP}$ exposure suppressed cell proliferation in the DG.

Notes: (A-D) Representative images of BrdU-labeled sections of the DG for each of the four groups: Vehicle, $\mathrm{SiO}_{2}-\mathrm{NPs}(\mathrm{I} 0 \mathrm{mg}), \mathrm{SiO}_{2}-\mathrm{NPs}(20 \mathrm{mg})$, and $\mathrm{SiO}-\mathrm{NPs}(50 \mathrm{mg})$. (E-H) The images are higher-power views of the boxed areas in A-D. (I) Quantitative analysis of the number of BrdU-labeled cells in the hippocampal DG. The data are presented as the mean $\pm \operatorname{SEM}(n=5) . * p<0.05$, and $* * * p<0.001$. The scale bar in $(\mathbf{D})=200 \mu \mathrm{m}$ and applies to $(\mathbf{A}-\mathbf{D})$, and that in $(\mathbf{H})=100 \mu \mathrm{m}$ and applies to $(\mathbf{E}-\mathbf{H})$. Abbreviations: $\mathrm{SiO}_{2}-\mathrm{NPs}$, silica nanoparticles; DG, dentate gyrus; BrdU, 5-bromo-2-deoxyuridine; SEM, standard error of the mean; GCL, granule cell layer.

the $\mathrm{SiO}_{2}-\mathrm{NPs}$ did not affect the immobility time in the FST (Figure 10E, $p>0.05$ ) or the TST (Figure 10F, $p>0.05$ ).

\section{Discussion}

In the present study, we found that $\mathrm{SiO}_{2}-\mathrm{NP}$ exposure during the first postnatal week resulted in inflammatory cell infiltration in the lung tissue, microglia over-activation in the hippocampal DG, and an increase in inflammatory cytokines in the hippocampus. Additionally, our data revealed that $\mathrm{SiO}_{2}-\mathrm{NP}$ exposure inhibited the proliferation of cell population and decreased the pool of NPCs in the DG. The behavioral tests further confirmed that $\mathrm{SiO}_{2}-\mathrm{NP}$ exposure during the early stage induced a significant deficit in social interaction and slight anxiety-like behavior.

A large body of evidence has been gathered to suggest that $\mathrm{SiO}_{2}-\mathrm{NP}$ exposure induces inflammatory response in the lung. ${ }^{26-30} \mathrm{We}$ demonstrate here that the exposure of neonatal mice to $\mathrm{SiO}_{2}-\mathrm{NPs}$ led to macrophages internalizing the
NPs and inflammatory cell infiltration. Microglia cells are regarded as macrophage-like cells that reside in the central nervous system (CNS) to mediate initial inflammation in the CNS. Several studies have described the consequences of NP exposure and also described the activation of microglia and the induction of increased cytokine production, such as TNF- $\alpha$, IL- $1 \beta$, and IL- 6 , in the frontal cortex, corpus striatum, and hippocampus. ${ }^{10,31} \mathrm{In}$ vitro, $\mathrm{SiO}_{2}$-NPs had been reported to bring about obvious inflammation in most cell lines, such as glia cells and epithelial cells. ${ }^{32-36}$ Our present results are consistent with these studies. $\mathrm{SiO}_{2}-\mathrm{NP}$ exposure of neonatal mice could cause obvious inflammation in the neonatal lung and brain.

Our previous studies have demonstrated that the early postnatal hippocampus is extremely vulnerable to neurotoxic stimuli. ${ }^{37,38}$ The present study further demonstrated a marked and significant increase in activated microglia in the DG and an increase in inflammatory cytokines in the hippocampus 

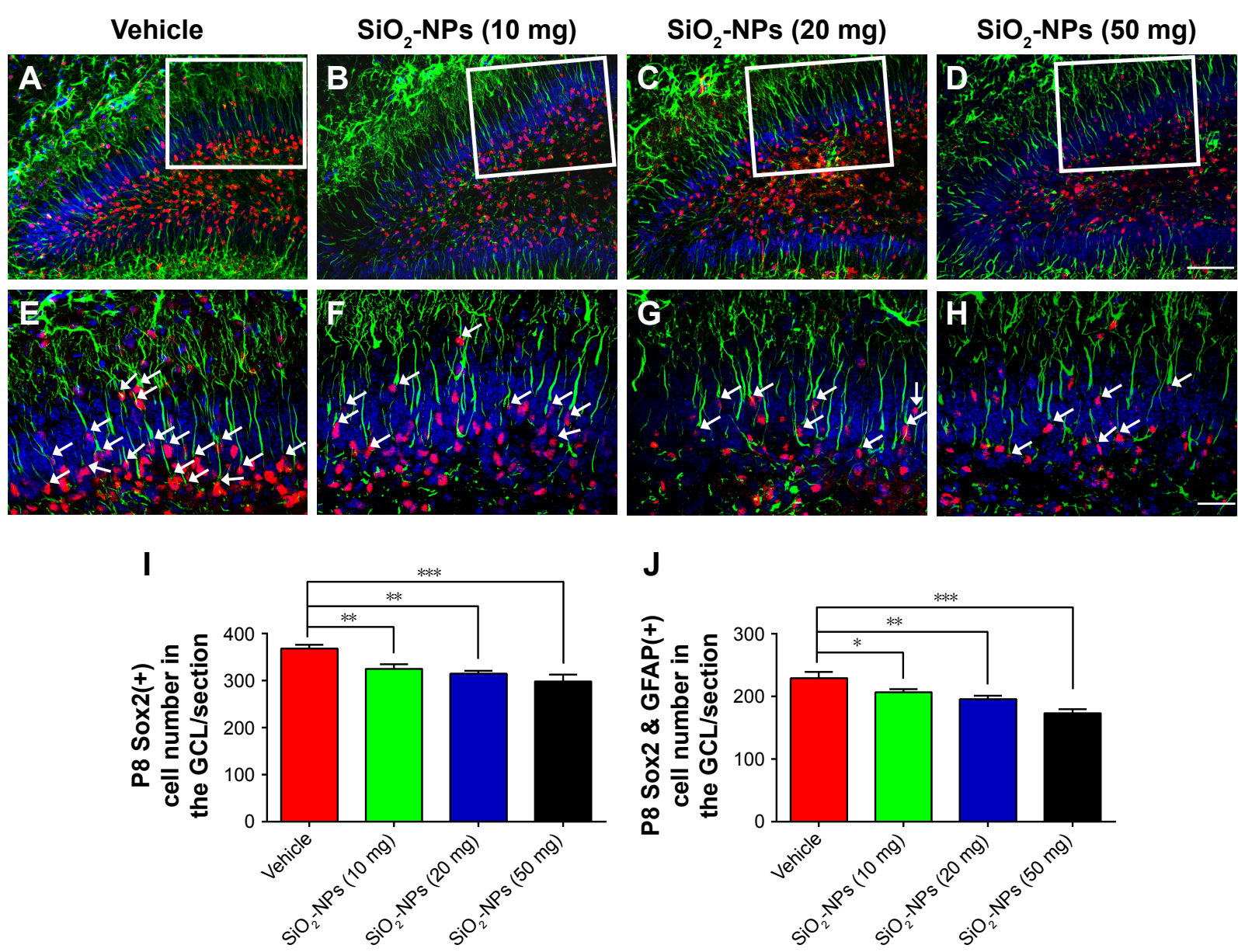

Figure 6 Exposure to $\mathrm{SiO}_{2}-\mathrm{NPs}$ reduced the RGCs labeled with GFAP and Sox2 in the DG.

Notes: (A-D) Representative images of Sox2 and GFAP double-positive RGCs in the DGs of the Vehicle, $\mathrm{SiO}_{2}-\mathrm{NPs}(10 \mathrm{mg}), \mathrm{SiO}_{2}-\mathrm{NPs}(20 \mathrm{mg})$, and SiO $-\mathrm{NPs}(50 \mathrm{mg})$. (E-H) Images are higher-power views in A-D. The arrows indicate the Sox2 and GFAP double-stained cells. (I) Quantitative analysis of the numbers of Sox2-positive cells in the GCL. (J) Quantitative analysis of the number of Sox $2^{+}$and GFAP ${ }^{+}$cells in the GCL. The data are presented as the mean $\pm S E M(n=5)$. ${ }^{*}<0.05$, $* * p<0.0 \mathrm{I}$, and $* * * p<0.00 \mathrm{I}$. The scale bar in $\mathbf{D}=50 \mu \mathrm{m}$ and applies to $\mathbf{A}-\mathbf{D}$, and that in $\mathbf{H}=20 \mu \mathrm{m}$ and applies to $\mathbf{E}-\mathbf{H}$.

Abbreviations: $\mathrm{SiO}_{2}-\mathrm{NPs}$, silica nanoparticles; RGCs, radial glial cells; GFAP, glial fibrillary acidic protein; Sox2, sex-determining region Y-box 2; DG, dentate gyrus; $\mathrm{GCL}$, granule cell layer; SEM, standard error of the mean.

of $\mathrm{SiO}_{2}$-NP-exposed mouse brains. There is also ample evidence demonstrating that inflammatory responses in neonates can subsequently negatively influence hippocampal neurogenesis. ${ }^{39,40}$ Our findings revealed that exposure to $\mathrm{SiO}_{2}$-NPs could inhibit hippocampal cell proliferation as assessed by BrdU in the DG at P8 in a dose-dependent manner. Sox 2 is one of the transcription factors that is highly expressed in the NPCs that are localized in the SGZ and determine the maintenance of NPC proliferation and selfrenewal. ${ }^{41}$ In the present study, we confirmed that the exposure of neonatal mice to $\mathrm{SiO}_{2}$-NPs significantly decreased Sox2-positive cells in the DG in a dose-dependent manner. It is well documented that RGCs determine the NPC pool in the postnatal DG and produce new granule neurons throughout life. In the present study, we noticed that $\mathrm{SiO}_{2}-\mathrm{NP}$ exposure depleted the $\mathrm{RGC}$ population labeled with
$\mathrm{GFAP}^{+} / \mathrm{SOX}^{+}$that can differentiate into NPCs. All of these findings suggest that NPCs may be a target of $\mathrm{SiO}_{2}$-NP-induced abnormalities in postnatal hippocampal development, which thereby may be involved in hippocampal-associated behavioral and cognitive deficits.

Studies have confirmed that the developmental exposure of rodents and zebrafish to NPs causes behavioral disruptions. ${ }^{42}$ In rodents, inhalation of ambient ultrafine particle air pollution may parallel with behavioral features of autism and other neurodevelopmental disorders. ${ }^{43}$ The three-chamber social test has been applied to study social preference and social novelty in mice. The results of this study demonstrate that mice treated with $\mathrm{SiO}_{2}-\mathrm{NPs}$ exhibited a comparable level of social preference. In the second part of the social interaction test, we evaluated social novelty. Mice that were exposed to $\mathrm{SiO}_{2}$-NPs exhibited significant deficit 

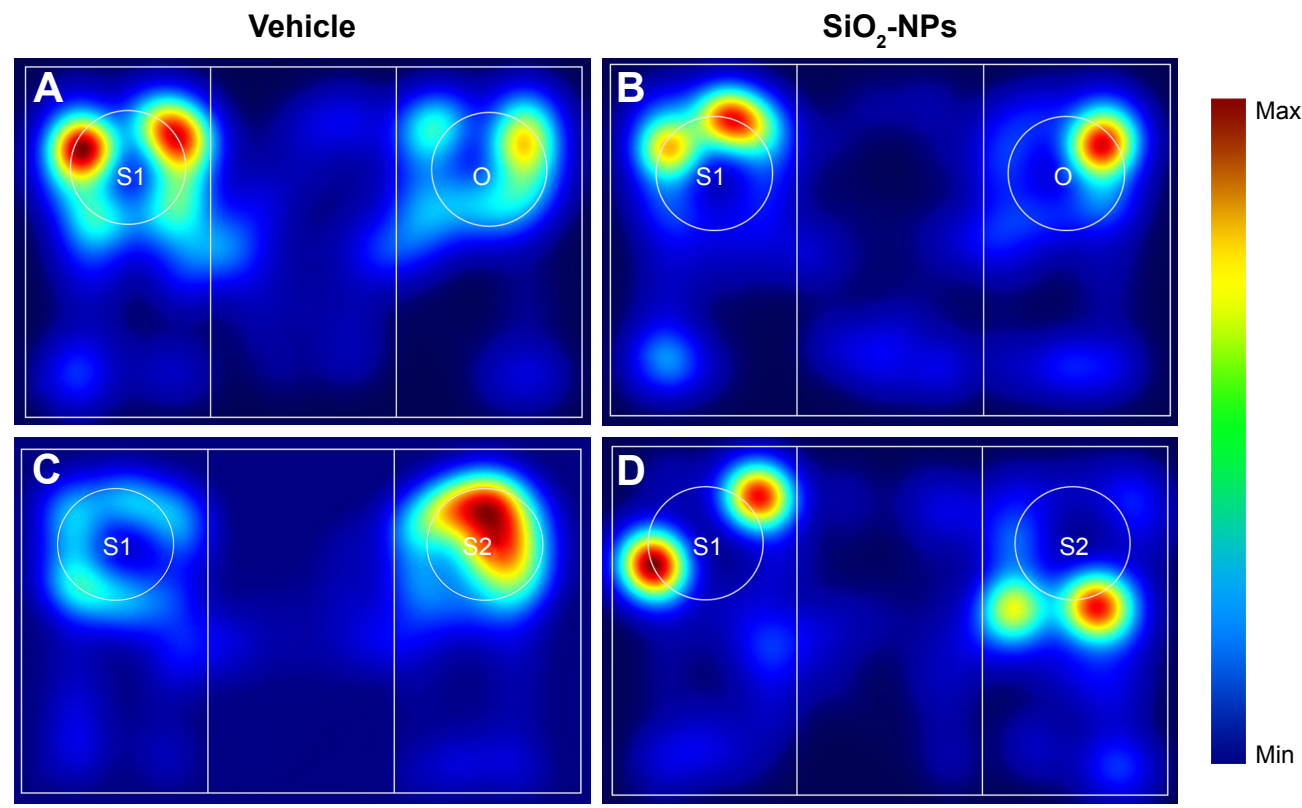

E

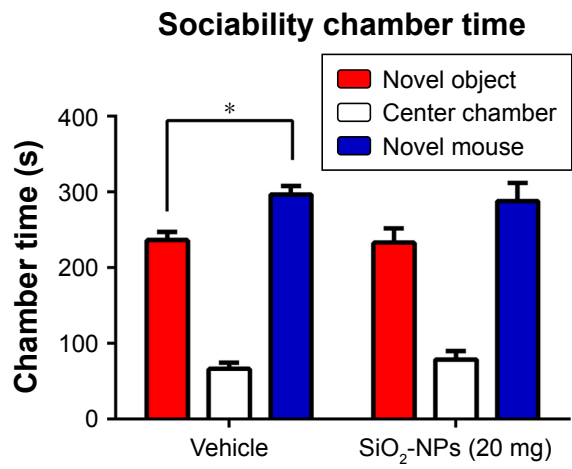

G

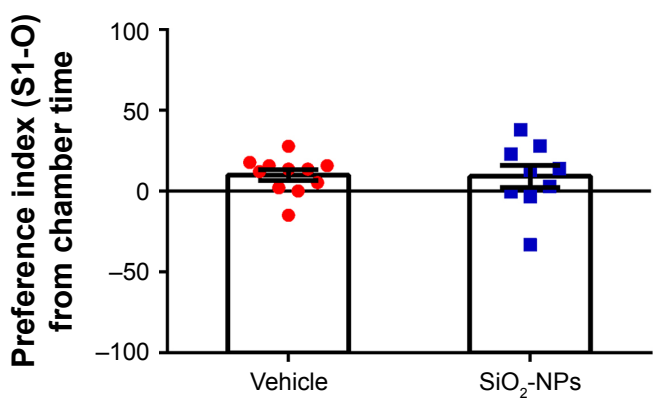

$\mathbf{F}$

Social novelty chamber time

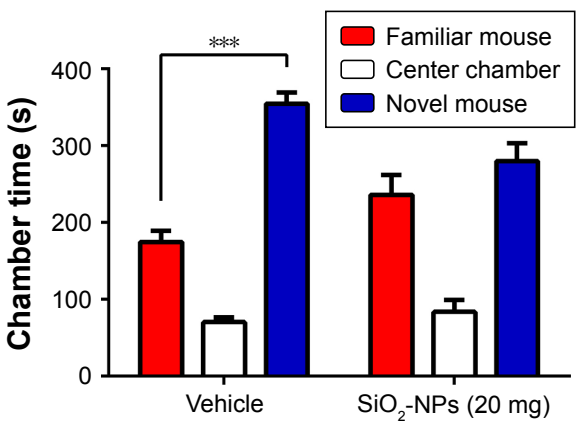

H

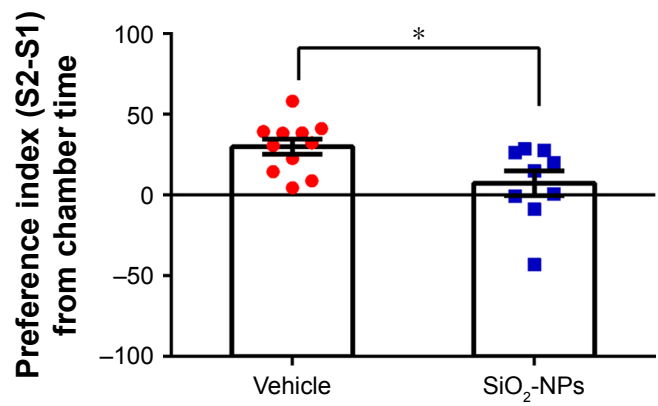

Figure $7 \mathrm{SiO}_{2}-\mathrm{NP}$-treated mice exhibited impairments in social novelty in the three-chamber sociability test.

Notes: (A-D) Heat maps representing the social interaction in the sociability and social novelty stages. (E) In the sociability phase, only vehicle-treated mice interacted more with the mouse than with an empty enclosure. (F) Control mice exhibited a significant preference for novel mouse compared with the familiar mouse, whereas $\mathrm{SiO}_{2}-\mathrm{NP}$ - exposed mice exhibited a characteristic lack of social novelty as demonstrated by approximately equal amounts of time with the novel mouse and familiar mouse. (G) Preference index (SI-O) based on chamber time. (H) Preference index (S2-SI) based on chamber time. All data expressed with the error bars represent the mean \pm $\mathrm{SEM}$ ( $\mathrm{n}=\mathrm{I}$ I for vehicle, $\mathrm{n}=9$ for the $\mathrm{SiO}_{2}-\mathrm{NP}$-treated group); ${ }^{*}<0.05, * * * p<0.00 \mathrm{I}$. Abbreviations: $\mathrm{SiO}_{2}-\mathrm{NPs}$, silica nanoparticles; SEM, standard error of the mean.

in social novelty and allocated equal time to exploring the familiar and novel mice. It is thought that general exploratory activity in the three-chambered apparatus is vulnerable to artifacts due to sedation or hyperactivity. We also noticed that $\mathrm{SiO}_{2}-\mathrm{NP}$ exposure did not cause sedation or hyperactivity as evaluated in the OFT. This lack of social recognition could not be explained by deficits in preference for novelty in general or recognition impairment because the $\mathrm{SiO}_{2}-\mathrm{NP}$ 
A

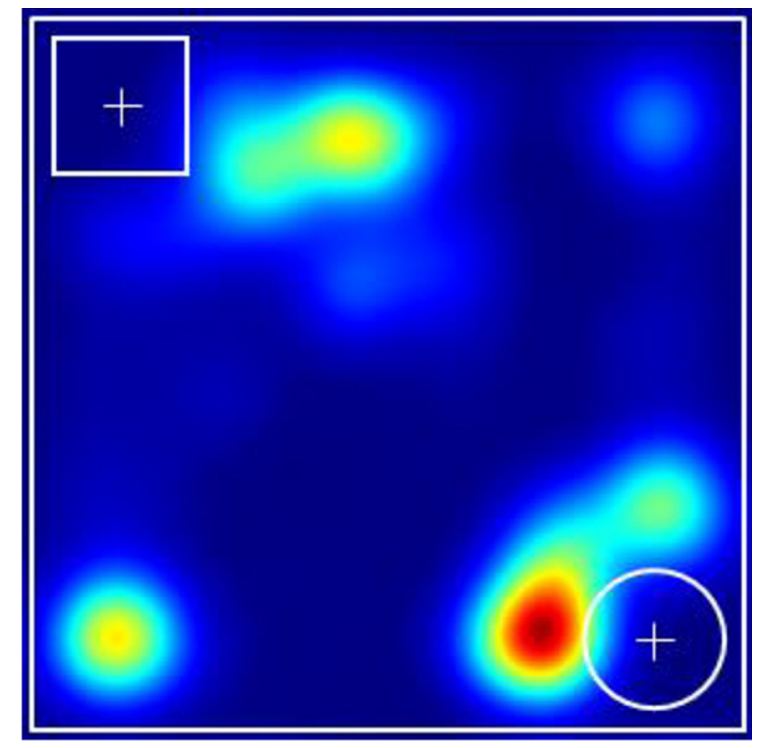

C

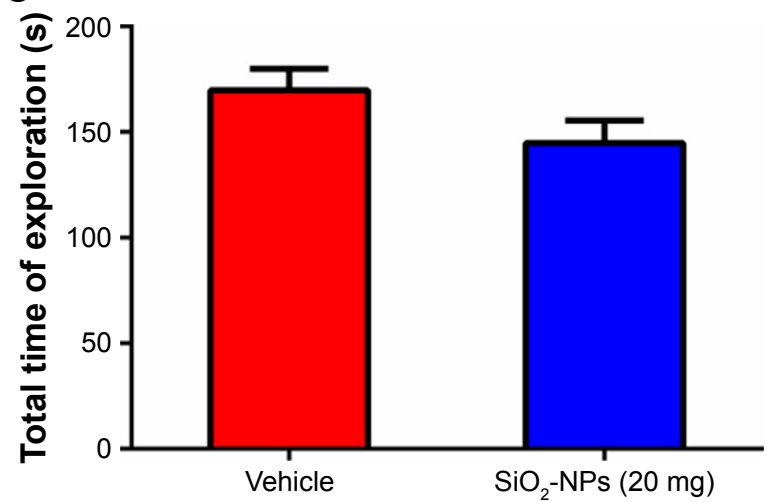

B $\mathrm{SiO}_{2}$-NPs (20 mg)

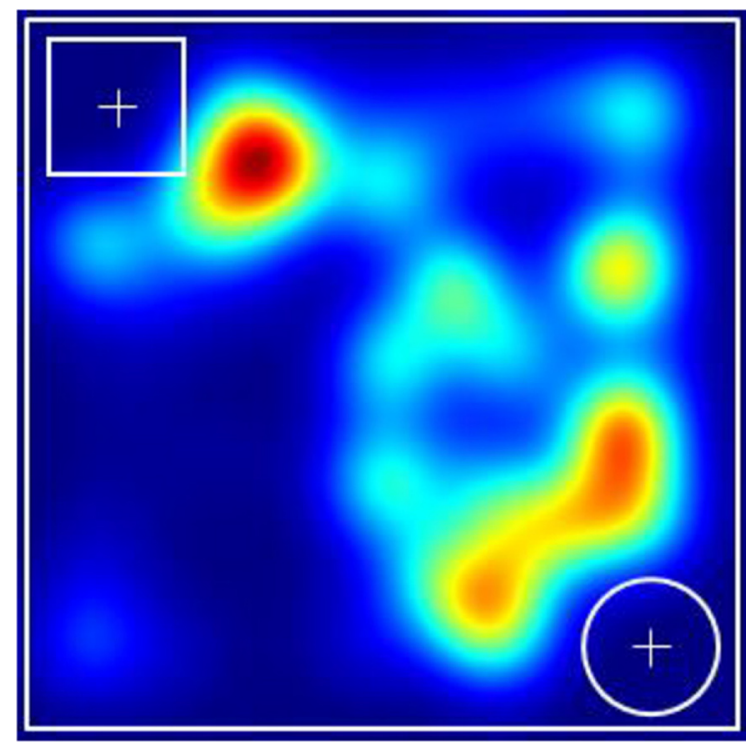

D

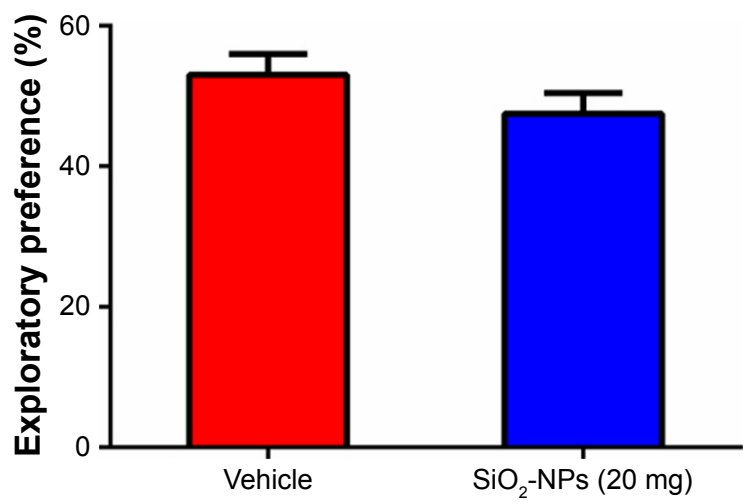

Figure $8 \mathrm{SiO}_{2}$-NP exposure in the neonatal period did not impair the short-term memory in adult mice.

Notes: (A and B) Representative heat maps of the resting times of mice with $\mathrm{SiO}_{2}-\mathrm{NP}$ exposure and control mice are presented. The cylindrical object is new, and the cuboid object is familiar. (C) There were no differences in the total time of exploration between the two groups. (D) $\mathrm{SiO}_{2}-\mathrm{NP}$ exposure did not affect the exploration preference. The data are presented as the mean \pm SEM ( $n=1$ I for vehicle, $n=9$ for the $\mathrm{SiO}_{2}-\mathrm{NP}$-treated group).

Abbreviations: $\mathrm{SiO}_{2}-\mathrm{NPs}$, silica nanoparticles; SEM, standard error of the mean.

exposure did not affect novel object preference. Therefore, postnatal $\mathrm{SiO}_{2}-\mathrm{NP}$ exposure induced social deficits were specific to the social context.

However, it has been reported that developmental disorders of the hippocampus can increase the risk of longterm behavioral changes, such as depression and anxiety. ${ }^{44}$ Although the percentage of time in the open arm by $\mathrm{SiO}_{2}-$ NP-treated mice was decreased in the EPM test, there were no significant differences in the percentages of entries into the open arm. We did not find any signs of anxiety in the light $\leftrightarrow$ dark test or OFT. Depression-like behaviors in mice were assessed in the FST and TST. We noticed that $\mathrm{SiO}_{2}-\mathrm{NP}$ exposure does not affect immobility time, which suggests that the inhalation of $\mathrm{SiO}_{2}$-NPs in early life may not lead to depression-like behavior in mice.
Many studies have revealed that the toxicity of $\mathrm{SiO}_{2}-\mathrm{NPs}$ is also related to the nanoparticle size and cell type. Similar to this study, $\mathrm{SiO}_{2}$-NPs of size $91 \mathrm{~nm}$ exposure induced apoptosis and inhibited cell proliferation in the cultured neural stem cell. ${ }^{45}$ Results of these studies indicated that the application of $\mathrm{SiO}_{2}$-NPs may cause a risk to the developing brain.

\section{Conclusion}

Overall, our data indicate that exposure to $\mathrm{SiO}_{2}$-NPs exerts neurotoxic effects in the hippocampal DG in mammals that subsequently disrupt social interaction in adults. With an increasing understanding of the detrimental health-related consequences of the extensive usage of $\mathrm{SiO}_{2}$-NPs and the potential environmental hazards, we will be able to alleviate human health risks. 

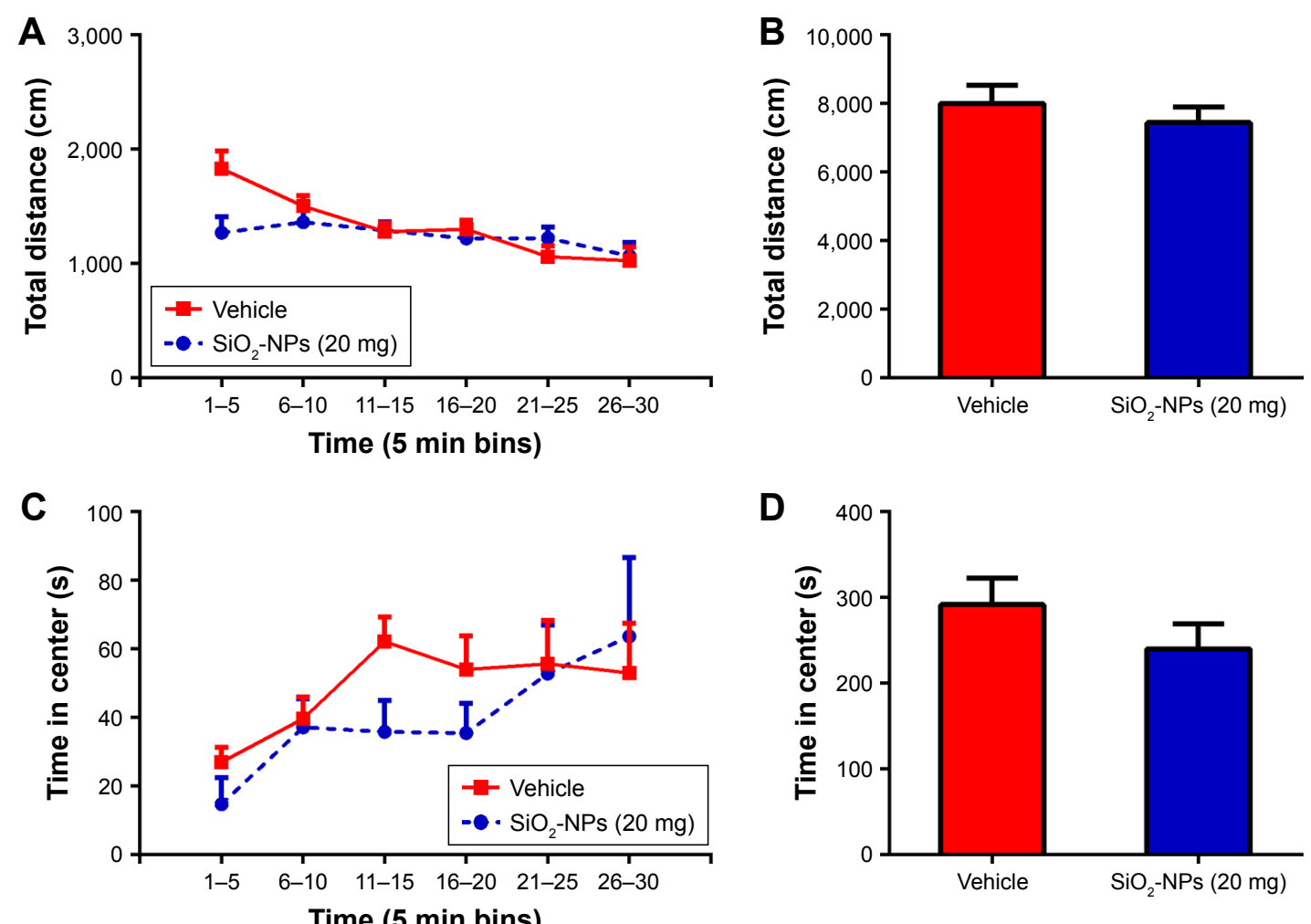

Figure $9 \mathrm{SiO}_{2}-\mathrm{NP}$ exposure did not induce a locomotion reduction.

Notes: The total distance traversed and center time were analyzed in 5-minute time bins over a 30-minute period in a novel open-field arena. ( $\mathbf{A}$ and $\mathbf{B}$ ) Mice in SiO NP-treated group exhibited no significant reductions in locomotor activity. (C and $\mathbf{D})$ No significant alterations were found in center time. All results are presented as the mean $\pm \mathrm{SEM}$ ( $\mathrm{n}=\mathrm{I}$ I for vehicle, $\mathrm{n}=9$ for the $\mathrm{SiO}_{2}-\mathrm{NP}$-treated group).

Abbreviations: $\mathrm{SiO}_{2}-\mathrm{NPs}$, silica nanoparticles; $\mathrm{SEM}$, standard error of the mean
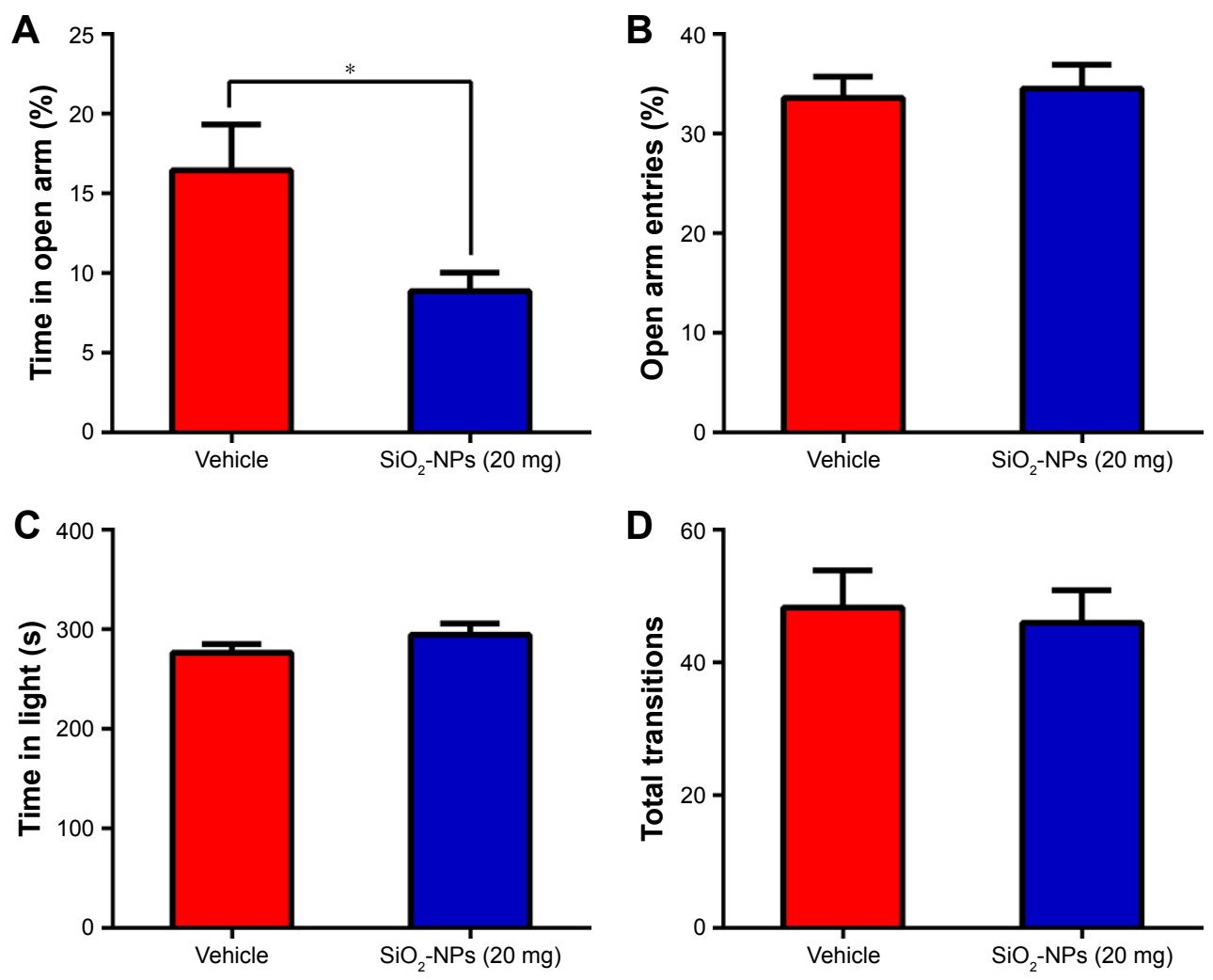

Figure 10 (Continued) 

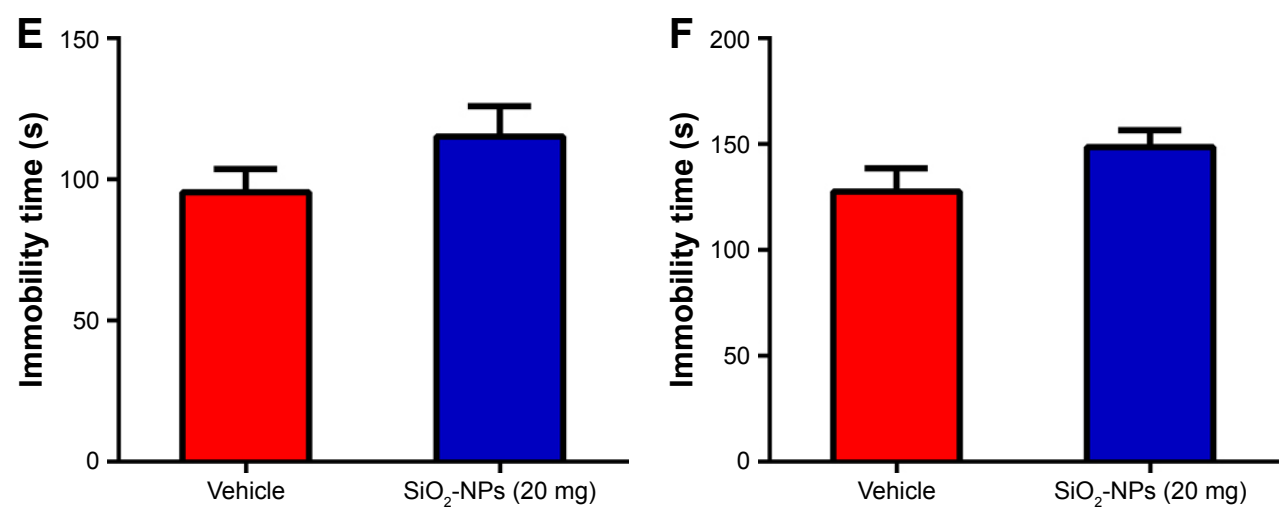

Figure 10 Effects of $\mathrm{SiO}_{2}-\mathrm{NP}$ exposure on anxiety-like and depressive-like behaviors.

Notes: (A) Percentage of time spent in the open arm, (B) percentage of entries into open arm in the plus maze are shown, (C) time in the light side of chamber, and (D) total number of transitions between the light and dark side of chamber. $\mathrm{SiO}_{2}-\mathrm{NP}$ exposure did not result in significant differences in immobility times in the last 4 min of the (E) FST or (F) TST. All results are presented as the mean \pm SEM ( $n=1$ I for vehicle, $n=9$ for the $\mathrm{SiO}_{2}-\mathrm{NP}$-treated group); ${ }^{*} p<0.05$.

Abbreviations: $\mathrm{SiO}_{2}-\mathrm{NPs}$, silica nanoparticles; SEM, standard error of the mean; FST, forced swimming test; TST, tail suspension test.

\section{Acknowledgments}

This study was supported by the National Nature Science Foundation of China (No 81701135, 31571069). We are grateful to Yulong Cai, Qin Zhang, Lian Wang, and Zhongke Wang for their kind help.

\section{Author contributions}

All authors contributed to data analysis, drafting, and revising the paper and agree to be accountable for all aspects of the work.

\section{Disclosure}

The authors report no conflicts of interest in this work.

\section{References}

1. Allen JL, Liu X, Weston D, et al. Developmental exposure to concentrated ambient ultrafine particulate matter air pollution in mice results in persistent and sex-dependent behavioral neurotoxicity and glial activation. Toxicol Sci. 2014;140(1):160-178.

2. Liljenström C, Lazarevic D, Finnveden G. Silicon-Based Nanomaterials in a Life-Cycle Perspective, Including a Case Study on Self-Cleaning Coatings. Stockholm: KTH Royal Institute of Technology; 2013.

3. Ali A, Suhail M, Mathew S, et al. Nanomaterial induced immune responses and cytotoxicity. J Nanosci Nanotechnol. 2016;16(1):40-57.

4. Armstead AL, Li B. Nanotoxicity: emerging concerns regarding nanomaterial safety and occupational hard metal (WC-Co) nanoparticle exposure. Int J Nanomed. 2016;11:6421-6433.

5. Choi J, Zheng QD, Katz HE, Guilarte TR. Silica-based nanoparticle uptake and cellular response by primary microglia. Environ Health Perspect. 2010;118(5):589-595.

6. Gilardino A, Catalano F, Ruffinatti FA, et al. Interaction of $\mathrm{SiO} 2$ nanoparticles with neuronal cells: ionic mechanisms involved in the perturbation of calcium homeostasis. Int J Biochem Cell Biol. 2015; 66:101-111.

7. Xu L, Dan M, Shao A, et al. Silver nanoparticles induce tight junction disruption and astrocyte neurotoxicity in a rat blood-brain barrier primary triple coculture model. Int J Nanomed. 2015;10:6105-6118.
8. Disdier C, Chalansonnet M, Gagnaire F, et al. Brain inflammation, blood brain barrier dysfunction and neuronal synaptophysin decrease after inhalation exposure to titanium dioxide nano-aerosol in aging rats. Sci Reports. 2017;7(1):12196.

9. Laakso MP, Lehtovirta M, Partanen K, Riekkinen PJ, Soininen H. Hippocampus in Alzheimer's disease: a 3-year follow-up MRI study. Biol Psychiatry. 2000;47(6):557-561.

10. Parveen A, Rizvi SH, Sushma, et al. Intranasal exposure to silica nanoparticles induces alterations in pro-inflammatory environment of rat brain. Toxicol Ind Health. 2017;33(2):119-132.

11. Shim KH, Jeong K-H, Bae SO, et al. Assessment of $\mathrm{ZnO}$ and $\mathrm{SiO}(2)$ nanoparticle permeability through and toxicity to the blood-brain barrier using Evans blue and TEM. Int J Nanomed. 2014;9(Suppl 2): 225-233.

12. Liu X, Sui B, Sun J. Blood-brain barrier dysfunction induced by silica NPs in vitro and in vivo: involvement of oxidative stress and Rho-kinase/JNK signaling pathways. Biomaterials. 2017;121:64-82.

13. Zhou L, Yin W, Ren W, et al. Controllable synthesis of Gd2O (CO3)2·H2O@silica-FITC nanoparticles with size-dependent optical and magnetic resonance imaging properties. New J Chem. 2012;36(12):2599-2606.

14. Xu L, Yang Y, Gao L, et al. Protective effects of resveratrol on the inhibition of hippocampal neurogenesis induced by ethanol during early postnatal life. Biochim Biophys Acta. 2015;1852(7):1298-1310.

15. He X, Sun D, Chen S, Xu H. Activation of liver X receptor delayed the retinal degeneration of rd1 mice through modulation of the immunological function of glia. Oncotarget. 2017;8(19):32068-32082.

16. Cai Y, Wang L, Xiao R, et al. Autism-like behavior in the BTBR mouse model of autism is improved by propofol. Neuropharmacology. 2017; 118:175-187.

17. Lee EJ, Lee H, Huang TN, et al. Trans-synaptic zinc mobilization improves social interaction in two mouse models of autism through NMDAR activation. Nat Commun. 2015;6:7168.

18. Becerril-Ortega J, Bordji K, Freret T, Rush T, Buisson A. Iron overload accelerates neuronal amyloid-beta production and cognitive impairment in transgenic mice model of Alzheimer's disease. Neurobiol Aging. 2014;35(10):2288-2301.

19. Lueptow LM. Novel object recognition test for the investigation of learning and memory in mice. J Vis Exp. 2017;(126):e55718.

20. Xu P, Xu H, Tang X, et al. Liver X receptor beta is essential for the differentiation of radial glial cells to oligodendrocytes in the dorsal cortex. Mol Psychiatry. 2014;19(8):947-957.

21. Flannery BM, Silverman JL, Bruun DA, et al. Behavioral assessment of NIH Swiss mice acutely intoxicated with tetramethylenedisulfotetramine. Neurotoxicol Teratol. 2015;47:36-45. 
22. Remmelink E, Aartsma-Rus A, Smit AB, Verhage M, Loos M, van Putten M. Cognitive flexibility deficits in a mouse model for the absence of full-length dystrophin. Genes BrainBehav. 2016;15(6):558-567.

23. Haj-Mirzaian A, Ostadhadi S, Kordjazy N, Dehpour AR, Ejtemaei Mehr S. Opioid/NMDA receptors blockade reverses the depressant-like behavior of foot shock stress in the mouse forced swimming test. Eur J Pharmacol. 2014;735:26-31.

24. Tian J, Zhang F, Cheng J, Guo S, Liu P, Wang H. Antidepressant-like activity of adhyperforin, a novel constituent of Hypericum perforatum $\mathrm{L}$. Sci Rep. 2014;4:5632.

25. Liu L, Zhang Q, Cai Y, et al. Resveratrol counteracts lipopolysaccharide-induced depressive-like behaviors via enhanced hippocampal neurogenesis. Oncotarget. 2016;7(35):56045-56059.

26. Morris AS, Adamcakova-Dodd A, Lehman SE, et al. Amine modification of nonporous silica nanoparticles reduces inflammatory response following intratracheal instillation in murine lungs. Toxicol Lett. 2016;241:207-215.

27. Yang M, Jing L, Wang J, et al. Macrophages participate in local and systemic inflammation induced by amorphous silica nanoparticles through intratracheal instillation. Int J Nanomed. 2016;11:6217-6228.

28. Sun B, Pokhrel S, Dunphy DR, et al. Reduction of acute inflammatory effects of fumed silica nanoparticles in the lung by adjusting silanol display through calcination and metal doping. ACS Nano. 2015;9(9): 9357-9372.

29. Rabolli V, Badissi AA, Devosse R, et al. The alarmin IL-1alpha is a master cytokine in acute lung inflammation induced by silica micro- and nanoparticles. Part Fibre Toxicol. 2014;11:69.

30. Downs TR, Crosby ME, Hu T, et al. Silica nanoparticles administered at the maximum tolerated dose induce genotoxic effects through an inflammatory reaction while gold nanoparticles do not. Mutat Res. 2012;745(1-2):38-50.

31. Czajka M, Sawicki K, Sikorska K, Popek S, Kruszewski M, KapkaSkrzypczak L. Toxicity of titanium dioxide nanoparticles in central nervous system. Toxicol In Vitro. 2015;29(5):1042-1052.

32. Lin W, Huang YW, Zhou XD, Ma Y. In vitro toxicity of silica nanoparticles in human lung cancer cells. Toxicol Appl Pharmacol. 2006; 217(3):252-259.

33. Wang JJ, Sanderson BJ, Wang H. Cytotoxicity and genotoxicity of ultrafine crystalline $\mathrm{SiO} 2$ particulate in cultured human lymphoblastoid cells. Environ Mol Mutagen. 2007;48(2):151-157.
34. Park E-J, Park K. Oxidative stress and pro-inflammatory responses induced by silica nanoparticles in vivo and in vitro. Toxicol Lett. 2009; 184(1):18-25.

35. Choi J, Zheng Q, Katz HE, Guilarte TR. Silica-based nanoparticle uptake and cellular response by primary microglia. Environ Health Perspect. 2010;118(5):589-595.

36. Skuland T, Ovrevik J, Lag M, Schwarze P, Refsnes M. Silica nanoparticles induce cytokine responses in lung epithelial cells through activation of a p38/TACE/TGF-alpha/EGFR-pathway and NF-kappaBeta signalling. Toxicol Appl Pharmacol. 2014;279(1):76-86.

37. Huang J, Jing S, Chen X, et al. Propofol administration during early postnatal life suppresses hippocampal neurogenesis. Mol Neurobiol. 2016;53(2):1031-1044.

38. Wang Z, He X, Fan X. Postnatal administration of memantine rescues TNF-alpha-induced decreased hippocampal precursor proliferation. Neurosci Lett. 2017;662:173-180.

39. Cui K, Ashdown H, Luheshi GN, Boksa P. Effects of prenatal immune activation on hippocampal neurogenesis in the rat. Schizophr Res. 2009;113(2-3):288-297.

40. Lee JH, Espinera AR, Chen D, et al. Neonatal inflammatory pain and systemic inflammatory responses as possible environmental factors in the development of autism spectrum disorder of juvenile rats. J Neuroinflammation. 2016;13(1):109.

41. Pevny LH, Nicolis SK. Sox2 roles in neural stem cells. Int J Biochem Cell Biol. 2010;42(3):421-424.

42. Li X, Liu B, Li XL, et al. SiO2 nanoparticles change colour preference and cause Parkinson's-like behaviour in zebrafish. Sci Rep. 2014; 4:3810.

43. Allen JL, Oberdorster G, Morris-Schaffer K, et al. Developmental neurotoxicity of inhaled ambient ultrafine particle air pollution: parallels with neuropathological and behavioral features of autism and other neurodevelopmental disorders. Neurotoxicology. 2017;59:140-154.

44. Green HF, Nolan YM. Inflammation and the developing brain: consequences for hippocampal neurogenesis and behavior. Neurosci Biobehav Rev. 2014;40:20-34.

45. Sun D, Gong L, Xie J, et al. Evaluating the toxicity of silicon dioxide nanoparticles on neural stem cells using RNA-Seq. Rsc Advances. 2017;7(75):47552-47564 


\section{Supplementary material}

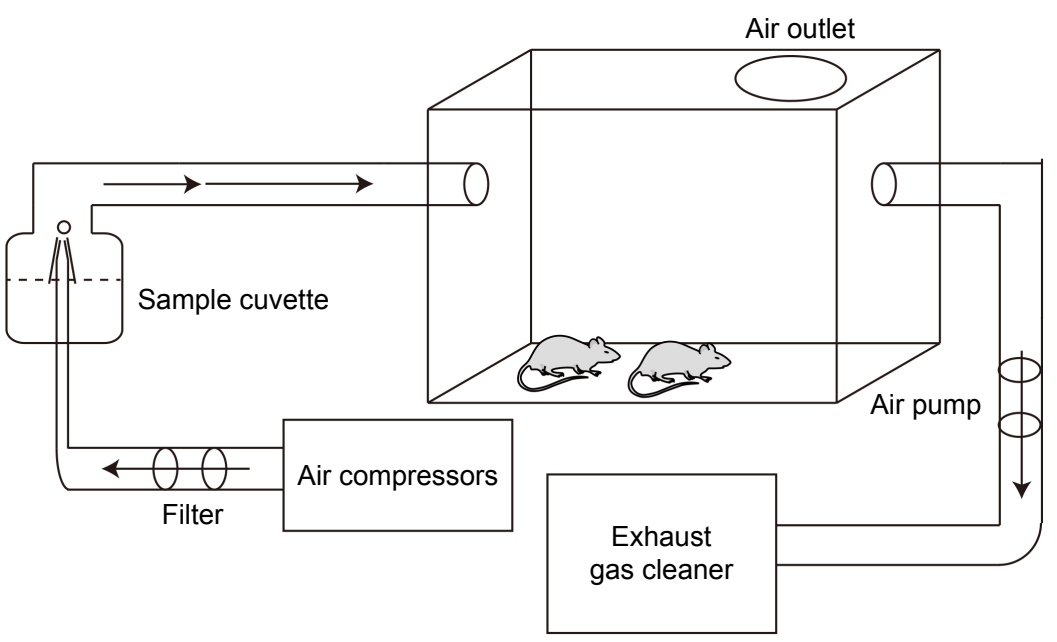

Figure SI Particle exposing system for experimental animals (schematic).

\section{Publish your work in this journal}

The International Journal of Nanomedicine is an international, peerreviewed journal focusing on the application of nanotechnology in diagnostics, therapeutics, and drug delivery systems throughout the biomedical field. This journal is indexed on PubMed Central, MedLine, CAS, SciSearch $®$, Current Contents ${ }^{\circledR} /$ Clinical Medicine,
Journal Citation Reports/Science Edition, EMBase, Scopus and the Elsevier Bibliographic databases. The manuscript management system is completely online and includes a very quick and fair peer-review system, which is all easy to use. Visit http://www.dovepress.com/ testimonials.php to read real quotes from published authors. 